\title{
Complutum
}

ISSN: 1131-6993

\section{El poblamiento de la Edad del Hierro en el suroeste de la Meseta Norte}

\author{
Jesús Rodríguez-Hernández ${ }^{1}$
}

Recibido: 24 de septiembre de 2019 / Aceptado: 4 de noviembre de 2019

Resumen. En este artículo se analiza la dinámica del poblamiento en el suroeste de la cuenca del Duero a lo largo de la Edad del Hierro ( $c$ a. 950-50 cal AC). Para ello, se examinan los diferentes patrones de poblamiento que se pueden distinguir en cada fase, así como las transformaciones y continuidades detectadas en el poblamiento durante este periodo. La Edad del Hierro en esta zona supone la plena sedentarización de los grupos humanos, que se apropiarán de manera efectiva del paisaje, a través de la construcción de poblados permanentes y necrópolis, así como de la configuración de los campos de cultivo y de las zonas de pastos. En este periodo asistimos a la emergencia de aldeas estables, que en un momento determinado se monumentalizan mediante el levantamiento de imponentes sistemas defensivos y, en algunos casos, dan origen a las primeras ciudades (u oppida) de esta zona. A nivel demográfico, la Edad del Hierro parece corresponderse con un momento de crecimiento poblacional que posibilitaría la transformación de aldeas ocupadas por unos pocos cientos de efectivos en ciudades habitadas por miles de personas.

Palabras clave: Edad del Hierro; Meseta Norte; patrones de poblamiento; aldeas; castros; oppida

\section{[en] The Iron Age settlement in the southwest of the Northern Meseta}

\begin{abstract}
This article analyses the settlement dynamics in the southwest of the Duero basin throughout the Iron Age (ca. 950-50 cal BC). To that end, the different settlement patterns that can be distinguished in each phase are examined, as well as the transformations and continuities detected in the settlement during this period. The Iron Age in this area marks the full sedentarisation of the human groups, who will effectively appropriate the landscape through the construction of permanent settlements and cemeteries, as well as the configuration of the crop fields and pasture areas. In this period, we witness the appearance of stable villages, which are eventually monumentalised through the erection of important defensive systems and, in some cases, leading to the first cities (or oppida) in this area. On a demographic level, the Iron Age seems to correspond with a population growth that would enable the transformation of villages occupied by just a few hundred of people into cities inhabited by thousands.
\end{abstract}

Keywords: Iron Age; North Meseta; settlement patterns; villages; hillforts; oppida.

Sumario. 1. Introducción. 2. El significado de la Edad del Hierro. 3. El tránsito Bronce Final-Hierro I. 4. La Primera Edad del Hierro y el proceso de sedentarización en poblados permanentes. 5. La transición Hierro I-Hierro II. 6. La Segunda Edad del Hierro y la aparición de las primeras ciudades. 7. Síntesis de un proceso. Bibliografía.

Cómo citar: Rodríguez-Hernández, J. (2019). El poblamiento de la Edad del Hierro en el suroeste de la Meseta Norte. Complutum, 30 (2): 391-413.

\section{Introducción}

En este trabajo llevamos a cabo un recorrido sintético por los orígenes y evolución de las primeras aldeas permanentes y ciudades que surgieron en el suroeste de la cuenca del Duero a lo largo de la Edad del Hierro y que han llegado en algunos casos (Ledesma, Salamanca o Coca) hasta nuestros días. Para ello, se parte de una conceptualización de este periodo que vincula su inicio al trascendental proceso de sedentarización de la población en asentamientos estables, ocurrido en los siglos iniciales del primer milenio a.C., y su final a la importante reorganización territorial realizada por Roma en la zona a partir de la segunda mitad del siglo I a.C. En este texto analizamos los factores, especialmente los demográficos, que desencadenaron la 
creación de estos asentamientos definitivos y su desarrollo posterior durante la Edad del Hierro, caracterizando además los diferentes patrones de poblamiento que se pueden vislumbrar en cada momento. El área de estudio escogida se encuentra delimitada por el río Duero y por las alineaciones montañosas del Sistema Central al norte y al sur, respectivamente; los ríos Cofio, Voltoya, Eresma y Adaja al este y los ríos Águeda y Duero al oeste (Fig. 1).

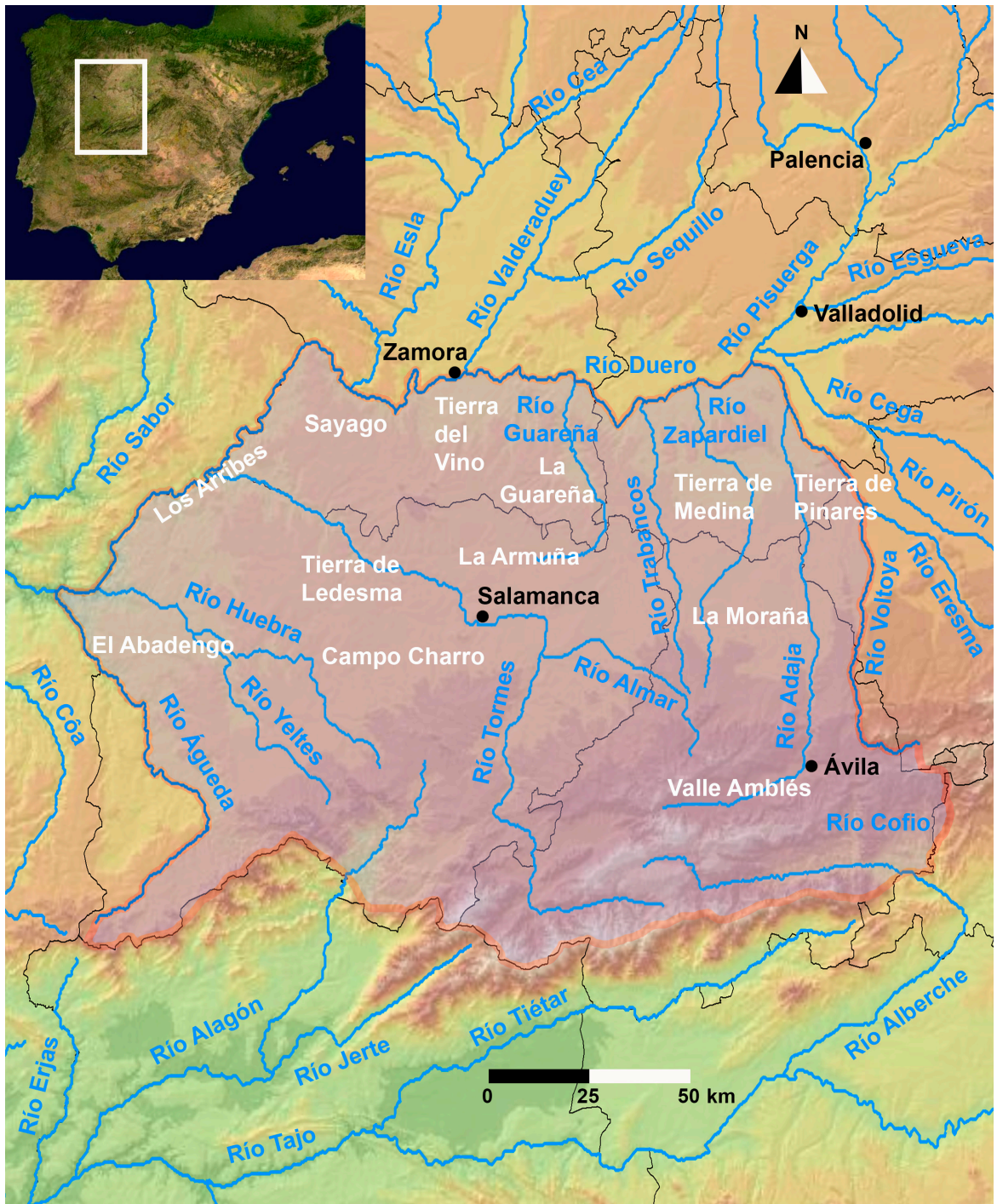

Figura 1. Delimitación del área de estudio y localización de los principales ríos y comarcas naturales e históricas de este espacio.

\section{El significado de la Edad del Hierro}

En 1836 Thomsen introdujo el Sistema de las Tres Edades, dividiendo así la Prehistoria en tres períodos caracterizados por una tecnología diferente: Edad de la Piedra, Edad del Bronce y Edad del Hierro (Rowley-Conwy 2007). Posteriormente, la clasificación tipológica de los artefactos procedentes de excavaciones de sitios tan señalados como Hallstatt y La Tène posibilitó la formulación por parte de Hildebrand (1874) de una división de la Edad del
Hierro en dos periodos, nombrados a partir de dichos yacimientos. En las décadas siguientes este marco cronológico se fue refinando mediante la subdivisión de sus dos fases y la adaptación a los diferentes contextos regionales europeos (Cunliffe 1999: 28-33). Por último, también a finales del siglo XIX, había un consenso emergente en la Europa continental acerca de identificar a la cultura de La Tène con los celtas descritos en las fuentes antiguas griegas y romanas (Champion 2006: 136). De esta manera, la Edad del Hierro pasó a con- 
figurarse como el periodo de tiempo que comienza cuando el hierro sustituye al bronce como elemento principal en la elaboración de armas y herramientas y acaba con la conquista de gran parte de Europa por Roma, alrededor del cambio de era (Wells 2011: 405). Además, la Edad del Hierro se correspondería con los pueblos prerromanos mencionados por los autores clásicos greco-latinos, especialmente los celtas.

En los últimos años esta definición tradicional de la Edad del Hierro, basada en criterios tecno-tipológicos, ha suscitado críticas entre algunos investigadores de la Protohistoria del cuadrante noroccidental de la Península Ibérica. Por una parte, critican el mantenimiento de esquemas de periodización puramente tipológicos y vacíos de contenido (Parcero 2000: 86; 2002: 19-20) y, por otra, el enfoque androcéntrico utilizado en la elaboración de esos esquemas cronológicos, al enfatizar el cambio tecnológico vinculado habitualmente al mundo masculino, frente a las actividades de mantenimiento más relacionadas con la esfera femenina (González Ruibal 2006-07: 65-66; Marín Suárez 2011: 225-226). Por todo ello, estos investigadores defienden la validez del uso del término "Edad del Hierro", pero tras una deconstrucción del mismo (al igual que se ha hecho en el caso del "Neolítico") y la dotación de un nuevo contenido (Parcero 2002: 19; Marín Suárez 2011: 226). Éste pasaría por ligar el inicio de la Edad del Hierro con el fundamental proceso de sedentarización en poblados estables, que se produjo en los primeros compases del primer milenio a.C. y que afectó a todo el conjunto de la sociedad (Parcero 2000: 86; Marín Suárez 2011: 226).

Este nuevo enfoque, que es el empleado en este trabajo, tiene los mismos problemas que la definición tecnológica tradicional para precisar una fecha para el comienzo de la Edad del Hierro, puesto que, al igual que la sustitución del bronce por el hierro fue gradual y sucedió en momentos diferentes en cada zona (Wells 2011: 405), el proceso de sedentarización parece haber seguido ritmos distintos en cada área. Así, en el noroeste de Portugal-suroeste de Galicia y el valle medio del Duero hay signos claros de sedentarización plena desde el siglo $\mathrm{X}$ cal AC (González Ruibal 2006-07: 67; Delibes y Romero 2011: 51), mientras que en el norte de Galicia, la región centro-occidental cantábrica, los rebordes montañosos de la cuenca del Duero, la Alta Extremadura o el valle me- dio del Tajo los primeros asentamientos estables aparecen hacia el 800 cal AC (González Ruibal 2006-07: 67; Marín Suárez 2011: 217; Blanco González 2010a: 370; Rodríguez Díaz 2009: 52-55; Torres Rodríguez 2013: 146).

\section{El tránsito Bronce Final-Hierro I}

El paso entre Cogotas I y el grupo Soto en la Meseta Norte ha sido planteado en numerosas ocasiones en términos rupturistas, debido a las diferencias que se pueden detectar a todos los niveles entre ambos mundos, llegándose a defender incluso la suplantación poblacional. Sin embargo, otros autores han sostenido la existencia de una transición gradual gestada en el seno de las comunidades cogoteñas e impulsada por influencias atlánticas, orientalizantes y de los Campos de Urnas (Blanco González 2010c: 157, con la bibliografía anterior). Una de las premisas más empleadas por los defensores de la cesura es la discontinuidad en el poblamiento, puesto que comprueban que rara vez los enclaves del Soto se levantan sobre los establecimientos cogotianos. El reciente análisis de Blanco González (2010c: 165-167) documenta, para el conjunto de Castilla y León, 650 yacimientos pertenecientes a la transición Bronce-Hierro y al Hierro Antiguo (1100-400 cal AC), de los cuales sólo 90 tienen una ocupación segura del Bronce Medio y/o Final (1800-1100 cal AC). Así pues, el 86\% son poblados de nueva planta, cifra muy diferente a la obtenida en su momento por Álvarez-Sanchís (2003: 77 y fig. 20) para las provincias de Ávila y Salamanca (38\% de fundaciones ex novo), aunque sobre una muestra de yacimientos muy escasa. Por nuestra parte, de 117 sitios de la Primera Edad del Hierro (ca. 950-400 cal AC) localizados en el suroeste de la Meseta Norte, 34 presentan vestigios previos pertenecientes a Protocogotas y/o Cogotas I Pleno/Avanzado, es decir, un $71 \%$ de los establecimientos son de nueva factura. Este porcentaje sería aún mayor $(84 \%)$ si sólo tuviéramos en cuenta la concurrencia de materiales pertenecientes a Cogotas I Pleno/Avanzado y Soto Inicial/grupo Soto (enclaves sin atribución a una fase concreta dentro del desarrollo del mundo soteño, debido a la escasez de materiales recuperados en los mismos o a su carácter no diagnóstico), presente en 19 yacimientos. Por otro lado, la comparecencia en un mismo emplazamiento de restos correspondientes a ambos complejos 
arqueológicos puede responder más que a una continuidad en el poblamiento a la coincidencia de intereses económicos sobre unos recursos muy concentrados (Quintana y Cruz 1996: 46). Pero también hay que tener presente que la erección de poblados de nueva planta no es una prueba incontrovertible de discontinuidad cultural, puesto que puede deberse a múltiples factores internos (sociales, económicos, demográficos, etc.) y no a la llegada de nuevas gentes.

Así, creemos que, junto a la posible llegada de nuevas tecnologías y conocimientos al interior peninsular en el marco de la precolonización (Celestino et al. 2008) y a los cambios acontecidos en el clima (López Sáez y Blanco González 2005), habría que prestar mayor atención a las dinámicas internas de los grupos que protagonizaron el mencionado cambio cultural. Estas comunidades, ante las condiciones de mayor aridez características de la fase final del periodo Subboreal, aparentemente pusieron en práctica dos tipos de estrategias: continuar con el modelo tradicional de poblamiento semipermanente, es decir, el establecimiento de las familias en un mismo lugar durante 3-5 años hasta que se constataba el agotamiento de la tierra (Delibes y Romero 2011: 64-66) o asentarse definitivamente en una localización privilegiada desde el punto de vista hídrico, como en el caso de Guaya (Berrocalejo de Aragona, Ávila) (Fig. 2). Quizá esta divergencia a la hora de afrontar este cambio en el régimen de lluvias tenga que ver con el tamaño de los grupos, siendo los menos numerosos los que seguirían trasladándose cada cierto tiempo a otra ubicación, como parece deducirse de la escasa superficie ocupada por algunos yacimientos del Soto Inicial como, por ejemplo, los tres situados en Montejo de Arévalo (Segovia), que en ningún caso alcanzan las 0,25 hectáreas ${ }^{1}$.

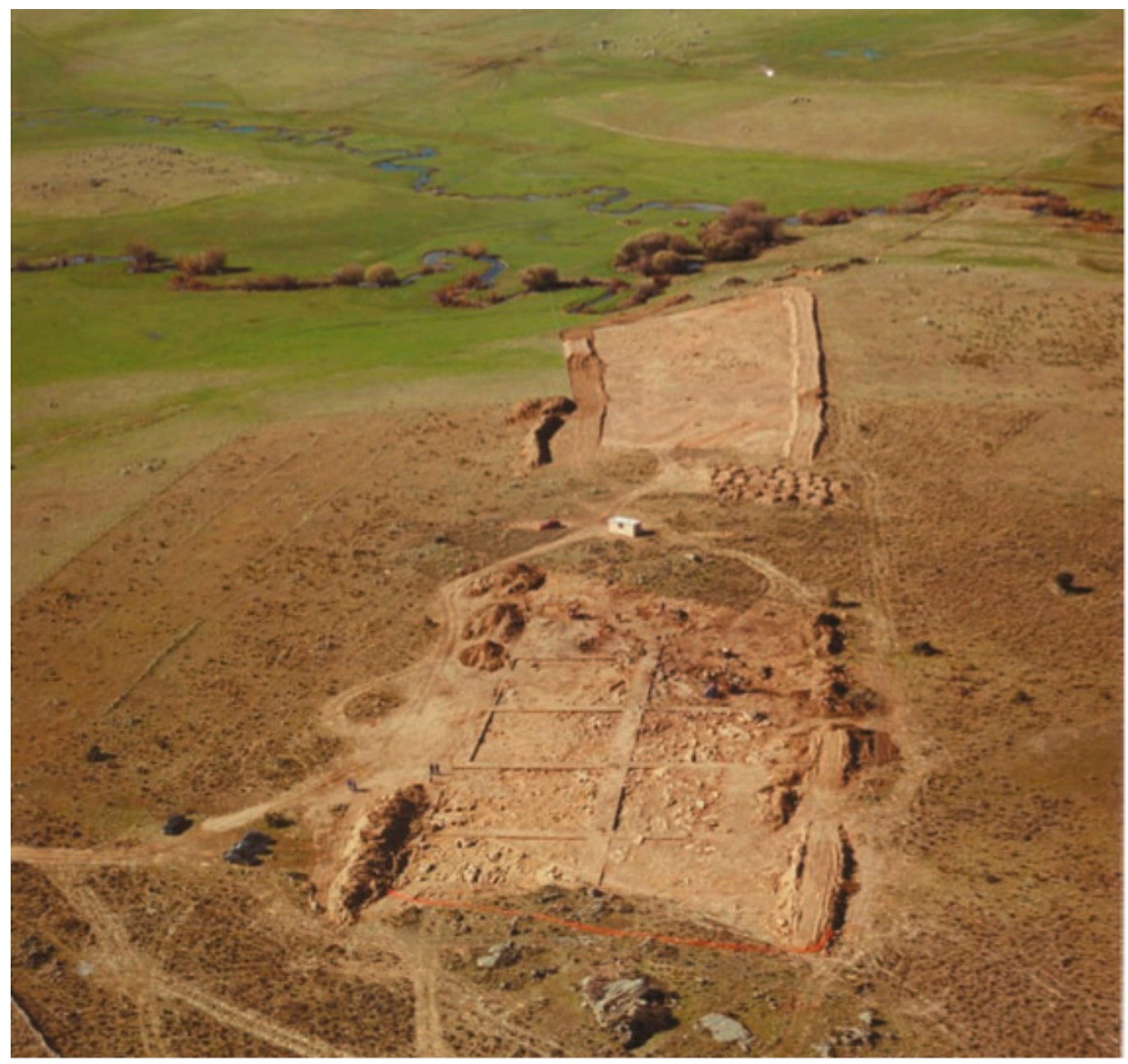

Figura 2. Vista área de la excavación arqueológica del yacimiento de Guaya, ubicado junto a la confluencia del arroyo de la Nava o de Berrocalejo y el río del Monte (según Misiego et al. 2005: lám. I). 


\section{La Primera Edad del Hierro y el proceso de sedentarización en poblados permanentes}

El establecimiento definitivo en poblados permanentes conlleva toda una serie de cambios económicos, sociales y cognitivos que modifican de manera irreversible la manera en que se percibe el mundo, las relaciones sociales y la explotación del medio. Además, posibilita otras transformaciones ulteriores como, por ejemplo, el aumento de la complejidad social o el incremento de las desigualdades sociales (Torres Rodríguez 2013: 146-147). A partir del Hierro Antiguo, se constata la inversión de una enorme cantidad de trabajo colectivo en la construcción de los poblados, que tendrá como resultado una importante alteración del paisaje anterior a través de la realización de obras como la erección de murallas o la excavación de fosos. De este modo, nos encontramos "ante una nueva forma de concebir no sólo las relaciones entre el ser humano y el paisaje sino de estructurar y gestionar a las propias comunidades" (Parcero 2000: 86).

A nivel económico la sedentarización supone una apuesta decidida por la agricultura y la ganadería como actividades que aseguren la supervivencia del grupo. Esto implica, entre otras cosas, la puesta en marcha de estrategias como el barbecho, el abonado animal y, quizá, la rotación de cultivos para garantizar la regeneración de los campos y con ello su fertilidad prolongada (Delibes y Fernández Manzano 2000: 115-117). Estas operaciones suponen una importante inversión de trabajo social, por lo que la apropiación efectiva de la tierra pasará a ser un elemento fundamental, con el objetivo de asegurar el acceso exclusivo a la misma por parte de la comunidad. De esta manera, se produciría la territorialización del paisaje que tendría como consecuencia el debilitamiento de la solidaridad intergrupal.

En términos sociales el asentamiento permanente de un grupo de familias en un enclave implica la pérdida de parte de su independencia y el respeto de una serie de obligaciones y derechos. Las familias constituyen las células básicas de producción y consumo, por lo que sus intereses particulares estarían en permanente contradicción con los de la comunidad en su conjunto. Así, aunque se habrían puesto en marcha mecanismos para contrarrestar esas tendencias disgregadoras, como la construcción de defensas artificiales -murallas y fosos- (Fernández-Posse y Sánchez-Palencia
1998: 138; Blanco González 2018: 317), la reciprocidad se limitaría fundamentalmente al ámbito familiar. Esto, unido al posible aumento de excedentes productivos para paliar las situaciones de escasez, supondría el caldo de cultivo para el desarrollo de las desigualdades sociales dentro de los poblados (Torres Rodríguez 2013: 147).

Finalmente, los cambios descritos en los ámbitos económico y social sólo son posibles porque en esta etapa se percibe el mundo de una manera distinta y este cambio cognitivo, a su vez, sólo se puede dar cuando los grupos actúan de un modo diferente (Hernando 2002: 151-152). Durante el Hierro Inicial se consolidaría la desacralización de la tierra iniciada en el Neolítico, por lo que, mientras en periodos anteriores se había producido una apropiación simbólica de la misma a través, por ejemplo, de la erección de monumentos megalíticos, ahora se llevará a cabo una apropiación efectiva del paisaje, a través de la construcción de poblados permanentes, la configuración de los campos de cultivo y de las zonas de pastos (Criado 1993; Hernando 2002: 147 y ss.). Desde este momento las comunidades organizarán su mundo de acuerdo al ciclo agrario, de manera que la agricultura y la ganadería pasarán a dominar no sólo el paisaje sino también el mundo cognitivo de las gentes de la Edad del Hierro (Williams 2003).

Antes de comenzar con el análisis de la ocupación del territorio por parte de las comunidades del Primer Hierro creemos necesario señalar las importantes diferencias territoriales en el volumen de información disponible. En el suroeste de la Meseta Norte hay un claro desequilibrio entre la zona oriental (sur de Valladolid, noroeste de Segovia y la mayor parte de la provincia de Ávila) y la occidental (sur de Zamora y Salamanca casi en su totalidad) (Fig. 3). Esta diferencia tan pronunciada, al menos en el caso del área oriental salmantina, podría deberse a discrepancias en los criterios utilizados en las campañas de prospección provinciales para la elaboración del Inventario Arqueológico de Castilla y León (Blanco González 2010c: 167). Para esta zona de la cuenca del Duero contamos con 24 yacimientos excavados, el $21 \%$ del total de asentamientos conocidos, pertenecientes tanto al Soto Inicial como al Pleno. Así, la mayor parte de los sitios sólo son conocidos mediante someras descripciones realizadas a partir de unos pocos restos materiales descubiertos en prospecciones de superficie. Por ello, 
su adscripción cronológica a la fase inicial o de plenitud del grupo Soto resulta problemática. En numerosas ocasiones los lotes cerámicos obtenidos en prospección son demasiado escasos como para permitir esta distinción (Quintana y Cruz 1996: 14). Esto explica por qué casi el $43 \%$ de los yacimientos del Hierro I ubicados en nuestra área de estudio están clasificados bajo la etiqueta genérica de "grupo Soto" (Fig. 4). Este elevado número de sitios sin una cronología más ajustada suponen un problema importante a la hora de definir los patrones de poblamiento característicos de cada fase. No obstante, a partir del análisis de los enclaves adscritos a un momento concreto del desarrollo del mundo del Soto, se pueden plantear ciertos rasgos generales sobre el tipo de emplazamiento elegido de forma preferente en cada etapa.

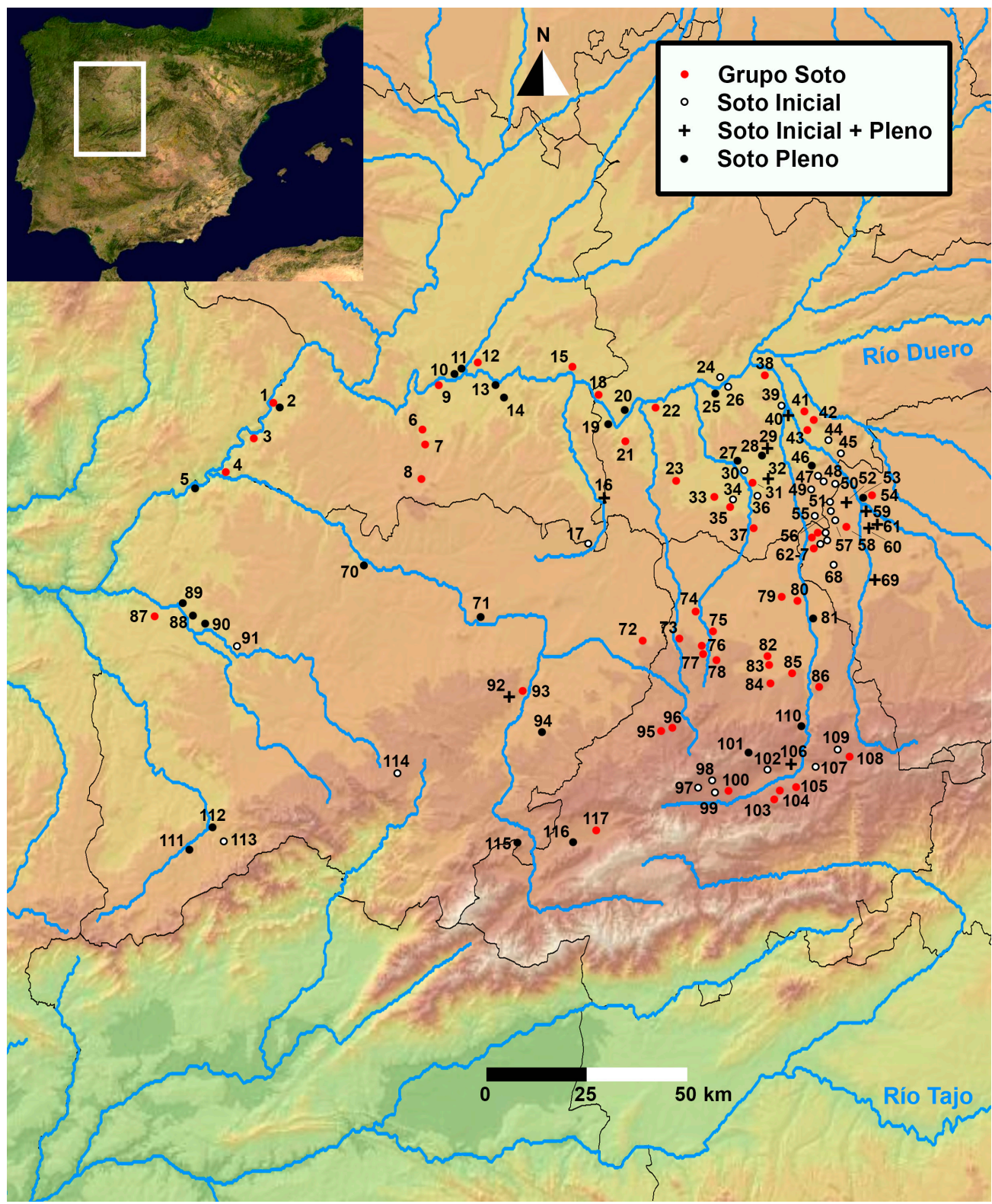

Figura 3. Poblamiento del Hierro I en el suroeste de la Meseta Norte: 1. Las Fraguas (Fariza); 2. El Castillo (Fariza); 3. El Castro (Villar del Buey); 4. Fermoselle; 5. Virgen del Castillo (Pereña de la Ribera); 6. Los Castillos (Las Enillas, Pereruela); 7. Los Castillos (La Tuda, Pereruela); 8. El Castillo (Peñausende); 9. El Castro (Zamora); 10. Zamora; 11. La Aldehuela (Zamora); 12. Valdegallinas II (Zamora); 13. Los Castros/Valcuevo (Villalazán); 14. El Viso (Madridanos); 15. Toro; 16. Cuesta El Pico (Castrillo de la Guareña); 17. Vallesa de la Guareña; 18. La Requejada (San Román de Hornija); 19. La Muela (Castronuño); 20. Casa del Barquero (Castronuño); 21. Las Alamedas (Castronuño); 
22. Los Calvillos II/El Barrero (Pollos); 23. El Cesto I (Nueva Villa de las Torres); 24. La Moraleja I (Tordesillas); 25. La Peña (Tordesillas); 26. Riberilla (La Seca); 27. La Mota (Medina del Campo); 28. San Antón I (Pozal de Gallinas); 29. El Lucero (Pozal de Gallinas); 30. Los Mártires I y II (Medina del Campo); 31. Las Quintanas II (Medina del Campo); 32. La Sarteneja/Prado Redondo (Moraleja de las Panaderas); 33. El Juncal (Velascálvaro); 34. Tobar (San Vicente del Palacio); 35. La Moralta (San Vicente del Palacio); 36. El Ciruelo (Medina del Campo); 37. El Torrejón/El Cubillo (Salvador); 38. El Espino (Villanueva de Duero); 39. El Matacán (Valdestillas); 40. Sieteiglesias (Matapozuelos); 41. El Pisón (Mojados); 42. Los Hornos (Alcazarén); 43. Cotarra Brazuelas II (Alcazarén); 44. Dehesa de Doña María (Olmedo); 45. La Dehesa (Pedrajas de San Esteban); 46. Cuesta Redonda (Olmedo); 47. La Monja (Aguasal); 48. Canales (Llano de Olmedo); 49. Fuente la Reina/La Olma (Fuente-Olmedo); 50. Eras de los Perros (Llano de Olmedo); 51. Los Casares (Fuente-Olmedo); 52. Tornacarros (Coca); 53. Cuesta del Mercado (Coca); 54. Las Negreras (Coca); 55. La Calzadilla (Puras); 56. La Vaca (Fuente de Santa Cruz); 57. El Merino (Coca); 58. Prado Arroyo/Vaca II (Coca); 59. Coca; 60. Pinar Nuevo/ Bodonazos (Coca); 61. El Clavo/Los Manaderos (Coca); 62. Las Guardillas(Montejo de Arévalo); 63. Fuente Tárraga (Montejo de Arévalo); 64. La Tesorera (Montejo de Arévalo); 65. Viña Mayor (Montejo de Arévalo); 66. Los Bodones II (Montejo de Arévalo); 67. Los Bodones I (Montejo de Arévalo); 68. Bocahierro (San Cristóbal de la Vega); 69. El Muerto (Juarros de Voltoya); 70. Ledesma; 71. Cerro de San Vicente (Salamanca); 72. Camino de Cantaracillo (Aldeaseca de la Frontera); 73. Sepulcro (Flores de Ávila); 74. La Iglesia (Cisla); 75. El Prayuso (Fontiveros); 76. Fuente de Jaraices (Rivilla de Barajas);

77. Cruz de San Marcos (Rivilla de Barajas); 78. Urracabezas II (Pascualgrande, Crespos); 79. Las Laderas (Nava de Arévalo); 80. Cerro de la Laguna (Nava de Arévalo); 81. La Tejeda (Orbita); 82. Prado Galindos II (Cabizuela); 83. Prado Galindos III (Cabizuela); 84. Riocabadillo (Riocabado); 85. Rompido de las Berlanas (Hernansancho); 86. Arroyo del Prado (Pozanco); 87. Las Merchanas (Lumbrales); 88. Los Castillos (Yecla de Yeltes); 89. Picón de la Mora (Encinasola de los Comendadores); 90. Yecla la Vieja (Yecla de Yeltes); 91. Los Castillos (Pozos de Hinojo); 92. Cerro de San Pelayo (Martinamor); 93. El Torrejón (Alba de Tormes); 94. El Guijo-El Castillo (Alaraz); 95. Los Guijares (Mirueña de los Infanzones); 96. Cerro de la Horca I (Mirueña de los Infanzones); 97. Las Zorreras (Muñana); 98. Los Arenalones (La Torre); 99. El Cogote II (La Torre); 100. Las Torrecillas (Santa María del Arroyo); 101. Los Castillejos (Sanchorreja); 102. La Lomilla (Muñopepe); 103. El Campillo (Gemuño); 104. El Pradillo (Gemuño); 105. Los Pajines (Ávila); 106. Cerro de la Cabeza (Ávila); 107. La Viña (Ávila); 108. Solana Angosta (Ávila); 109. Guaya (Berrocalejo de Aragona); 110. Las Cogotas (Cardeñosa); 111. El Castillo (Herguijuela de Ciudad Rodrigo); 112. Lerilla (Zamarra); 113. Los Castillejos (Zamarra); 114. Castil de Cabras (San Miguel de Valero); 115. Las Paredejas (Medinilla); 116. Castillo Bayuela (Hoyorredondo); 117. Cerro del Río (Mesegar de Corneja).

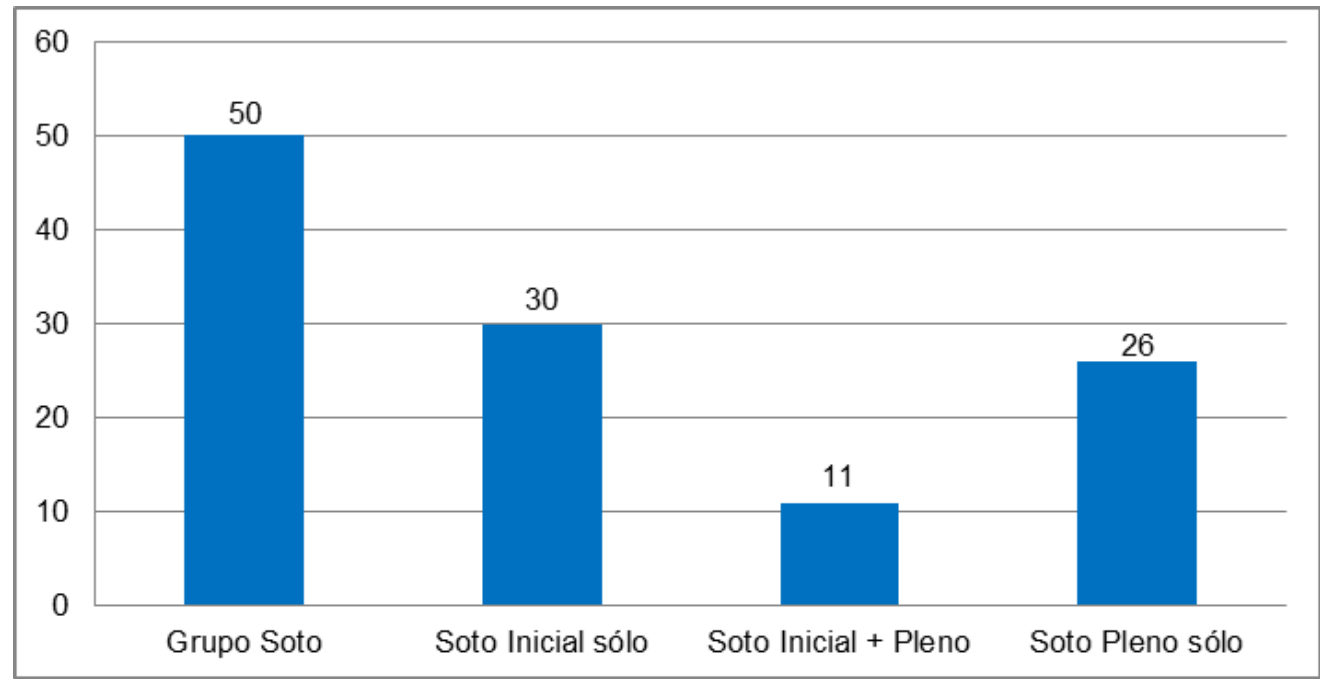

Figura 4. Adscripción crono-estilística de las cerámicas de los poblados del Hierro Antiguo en el suroeste de la cuenca del Duero. 
De esta manera, el poblamiento del Soto Inicial ( $c a$. 950-800 cal AC) se caracterizaría, en primer lugar, por presentar una distribución concentrada fundamentalmente en dos sectores del área de estudio: el Valle Amblés y las campiñas de la zona nororiental (comarcas de la Tierra de Medina y la Tierra de Pinares). En dichos sectores se encuentra el $85 \%$ de los asentamientos adscritos a la fase inicial del grupo Soto y los 13 yacimientos de esta fase que presentan vestigios previos pertenecientes a las distintas etapas de Cogotas I. Esto se debe a que estas dos zonas forman parte del área de poblamiento recurrente de los grupos prehistóricos meseteños desde al menos el Neolítico (Blanco González 2010a). Fuera de estos dos ámbitos espaciales contamos con los dos enclaves del Soto Inicial recientemente localizados en La Guareña (Portilla Casado 2015), el enterramiento tumular del Cerro de San Pelayo (Martinamor, Salamanca) (López Jiménez y Benet 2004) y tres sitios ubicados en el occidente y sur de la provincia de Salamanca, aunque la cultura material de estas tres últimas estaciones esté más emparentada con los ámbitos cacereño y beirano (López Jiménez 2003: 168-179).

En el Valle Amblés los diferentes estudios espaciales realizados han detectado un cambio notable en el patrón de poblamiento a partir de la etapa inicial del mundo soteño (Fabián 1999; López Sáez et al. 2009). En este momento se ha constatado la elección de emplazamientos alejados de las zonas más bajas del valle, por lo que los poblados se establecerán en los rebordes serranos en las cercanías de cursos fluviales secundarios. Posiblemente, este cambio en las pautas de asentamiento se debería al agotamiento de las tierras del fondo del valle, provocado por el uso reiterado del fuego para aclarar la vegetación. De este modo, ahora los yacimientos ocuparán la ladera de las estribaciones serranas que bordean el valle o lomas elevadas sobre los terrenos sedimentarios de la fosa del Amblés (Fig. 5), buscando así un fácil acceso a un amplio abanico de recursos agropecuarios. Estos enclaves del Soto Inicial se encuentran a una altitud muy similar (entre los 1080 y los 1150 m s.n.m.), pero su tamaño, medido a partir de los restos encontrados en superficie, es más diverso, ya que hay sitios como La Lomilla (Muñopepe, Ávila) o La Viña (Ávila capital) que no alcanzan la hectárea y estaciones como El Cogote II (La Torre, Ávila) que ocupa una superficie aproximada de 13,5 ha. Su distribución por el Valle Amblés es bastante equilibrada aunque el mencionado asentamiento de El Cogote II y el yacimiento de Los Arenalones (La Torre, Ávila) sólo estén separados $1600 \mathrm{~m}$ en línea recta (Blanco González 2009a: vol. II (1): 197198). La relativa situación de prominencia en el paisaje del primero y su mayor tamaño pueden llevar a pensar en una subordinación del núcleo de Los Arenalones. Sin embargo, su cercanía puede explicarse también a partir de una hipotética ocupación sucesiva de estos sitios, primero en Los Arenalones y en un momento más avanzado en El Cogote II. Sobre el carácter permanente de los enclaves repartidos por el valle puede aducirse la entidad de los restos encontrados en Guaya y su prolongada ocupación (Misiego et al. 2005). Asimismo, la cultura material hallada en el Cerro de la $\mathrm{Ca}$ beza, en Ávila capital, parece indicar que esta estación pudo estar ocupada durante las dos fases del grupo Soto (Blanco González 2009a: vol. II (1): 68-76).

En las campiñas de la Tierra de Medina y la Tierra de Pinares los distintos trabajos espaciales llevados a cabo en los últimos años han constatado una clara asociación del poblamiento del Soto Inicial a los recursos hídricos de la zona, especialmente a los numerosos humedales localizados en estas comarcas, en forma de lagunas, charcas, bodones y lavajos (Quintana y Cruz 1996: 43-44; Blanco García 2006b: 291-295). Este patrón de poblamiento es muy similar al detectado entre los grupos de Cogotas I por lo que no debe extrañar la presencia de cerámicas cogoteñas en 10 de los asentamientos de la fase inicial del Soto de esta área. Esta coincidencia, como ya se ha comentado, se debería posiblemente a la concentración en esta zona de terrenos aptos para el desarrollo de su economía mixta. En este momento los yacimientos se establecen en el llano o en relieves alomados de escasa entidad, a una altitud que oscila entre los 660 y los 866 m s.n.m. Su tamaño varía bastante puesto que hay numerosos enclaves pequeños que no alcanzan la hectárea de superficie, una cantidad similar de sitios con una extensión entre 1 y 10 ha $\mathrm{y}$, finalmente, cinco estaciones vallisoletanas cuya superficie oscila entre las 12 y las 29,5 ha: Dehesa de Doña María, El Ciruelo, La Dehesa, La Sarteneja/Prado Redondo y Sieteiglesias. A pesar de estas diferencias de tamaño no parece haber elementos suficientes para pensar en una jerarquización de las estaciones 
soteñas en esta etapa inicial. En la Tierra de Pinares segoviana la distribución de los poblados muestra cierta regularidad, con una media de $3358 \mathrm{~m}$ de distancia con respecto al vecino más próximo (Blanco García 2006b: 473), lo que da una idea de la elevada densidad del poblamiento comarcal. De todos modos, hay que tener en cuenta que buena parte de los núcleos de pequeño tamaño serían simples "puntos de habitación recurrentes, [...] establecimientos de dos o tres familias nucleares o una sola fa- milia extensa" (ibid.: 286-287). Entre los posibles asentamientos permanentes en esta zona habría que incluir, al menos, algunos de los yacimientos que presentan continuidad entre las dos fases del grupo Soto y que están ubicados en posiciones especialmente privilegiadas desde el punto de vista hídrico, como es el caso de la estación segoviana de Los AzafranalesCoca (Blanco García 2006b: 196-209) y del poblado de Sieteiglesias (Matapozuelos, Valladolid) (Bellido y Cruz 1993).

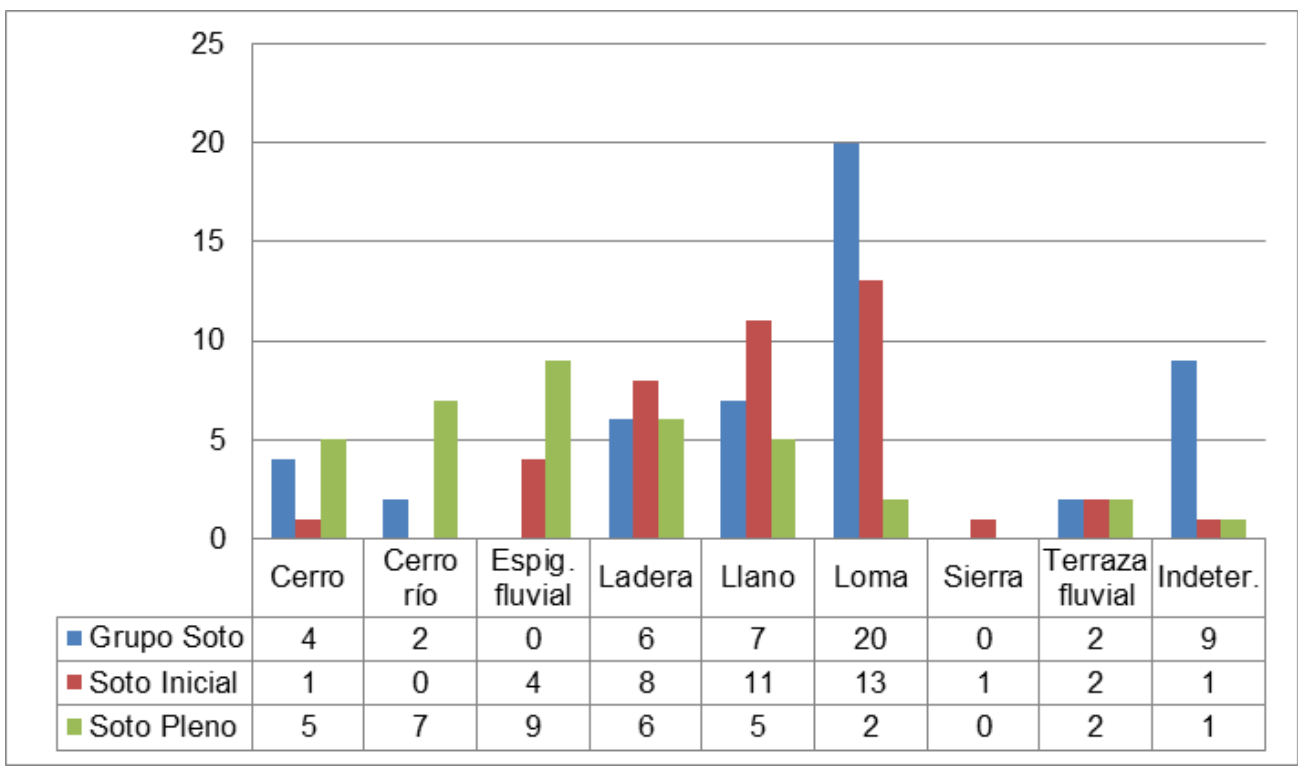

Fig. 5. Tipos de emplazamiento de los núcleos del Hierro I en el suroeste de la Meseta Norte.

Por su parte, el poblamiento del Soto Pleno ( $c$. 800-400 cal AC) en el suroeste de la Meseta Norte se distribuye fundamentalmente a lo largo de los cauces fluviales principales, es decir, el río Duero y sus afluentes más importantes. Este hecho se explica por la necesidad de abastecer de agua a grupos más numerosos y concentrados en núcleos permanentes, que albergarían contingentes de 200-300 personas (Blanco García 2006b: 453; Macarro y Alario 2012: 54); pero también porque espigones y cerros elevados sobre los ríos constituyen algunos de los puntos de mayor altitud relativa en esta área (Blanco González 2009a: vol. I: 432 y 490). Por ello, la territorialización en este momento parece ajustarse a los valles de los ríos, donde las comunidades buscarían acceder a una diversidad de recursos complementarios. Las aldeas controlarían unos territorios relativamente extensos, ya que la distancia media entre ellas es superior a los $10 \mathrm{~km}$ (ibid.: 432433 y 490-491). Durante esta fase las zonas más densamente pobladas en la etapa anterior, el Valle Amblés y la Tierra de Pinares, serán ocupadas con una menor intensidad (Quintana y Cruz 1996: 48; Blanco González 2009a: vol. I: 433). A partir de esta constatación diversos autores han planteado un "movimiento migratorio" a nivel regional, que produciría un trasvase de población desde las áreas tradicionales de asentamiento hacia espacios hasta ahora poco atrayentes, como la Tierra de Campos, la Campiña de Villalar (Quintana y Cruz 1996: 48-50), las zonas serranas del occidente de Zamora y el norte de Soria y sectores periféricos de la Meseta Norte pertenecientes a las provincias de Soria, Burgos, León, Zamora y Salamanca (Blanco González 2010a). Este fenómeno respondería a un importante crecimiento demográfico (Esparza 1995: 140; Fernández- 
Posse 1998: 154), favorecido por las nuevas condiciones climáticas del Subatlántico, y a la creciente presión humana sobre el entorno debido a la sedentarización definitiva en aldeas, que haría necesaria la colonización de nuevos terrenos fértiles para asegurar la supervivencia del grupo (Quintana y Cruz 1996: 50). Dicha colonización se habría llevado a cabo de manera descoordinada, en momentos distintos del Hierro Antiguo, mediante movimientos migratorios de corto alcance a lo largo de algunos de los principales valles fluviales de la Meseta (Blanco González 2010a: 372). El resultado de este proceso habría sido la fundación de nuevas aldeas a partir del excedente demográfico de los enclaves ya existentes, mediante la duplicación o segmentación de las comunidades cada cinco o seis generaciones (Ortega Ortega 1999: 433-440; Esparza 2009: 34).

En esta fase de plenitud la cabecera del río Adaja o Valle Amblés estaría dentro del área de influencia de Los Castillejos de Sanchorreja (Ávila) (González-Tablas y Domínguez Calvo 2002) y posiblemente del Cerro de la Cabeza, aunque este último sitio pudo abandonarse ha- cia el s. VII a.C. (Blanco González 2009a: vol. II (1): 71). Río abajo encontramos el yacimiento de Las Cogotas (Cardeñosa, Ávila), cuya difusa ocupación durante esta etapa ha sido recientemente revisada (Blanco González 2010b). A continuación, en plena Moraña se sitúa La Tejeda (Orbita, Ávila) (Blanco González 2009a: vol. II (2): 81-86) y en la confluencia con el río Eresma la estación de Sieteiglesias (Fig. 6). Este último curso fluvial presenta también a partir de su tramo medio-bajo un poblamiento lineal protagonizado por dos importantes asentamientos localizados en el término municipal de Coca, el ya mencionado de Los Azafranales y la Cuesta del Mercado (Blanco García 1994). Cuesta Redonda en Olmedo (Valladolid), aunque alejado del cauce del río, sería el siguiente enclave de referencia debido a la entidad de sus restos y a su ubicación en un lugar destacado del paisaje (Blanco González 2009a: vol. I: 432). Con respecto al río Zapardiel, en su curso bajo sobresale la aldea situada sobre el cerro de La Mota (Medina del Campo, Valladolid), en una posición destacada sobre la planicie circundante (Seco y Treceño 1995).

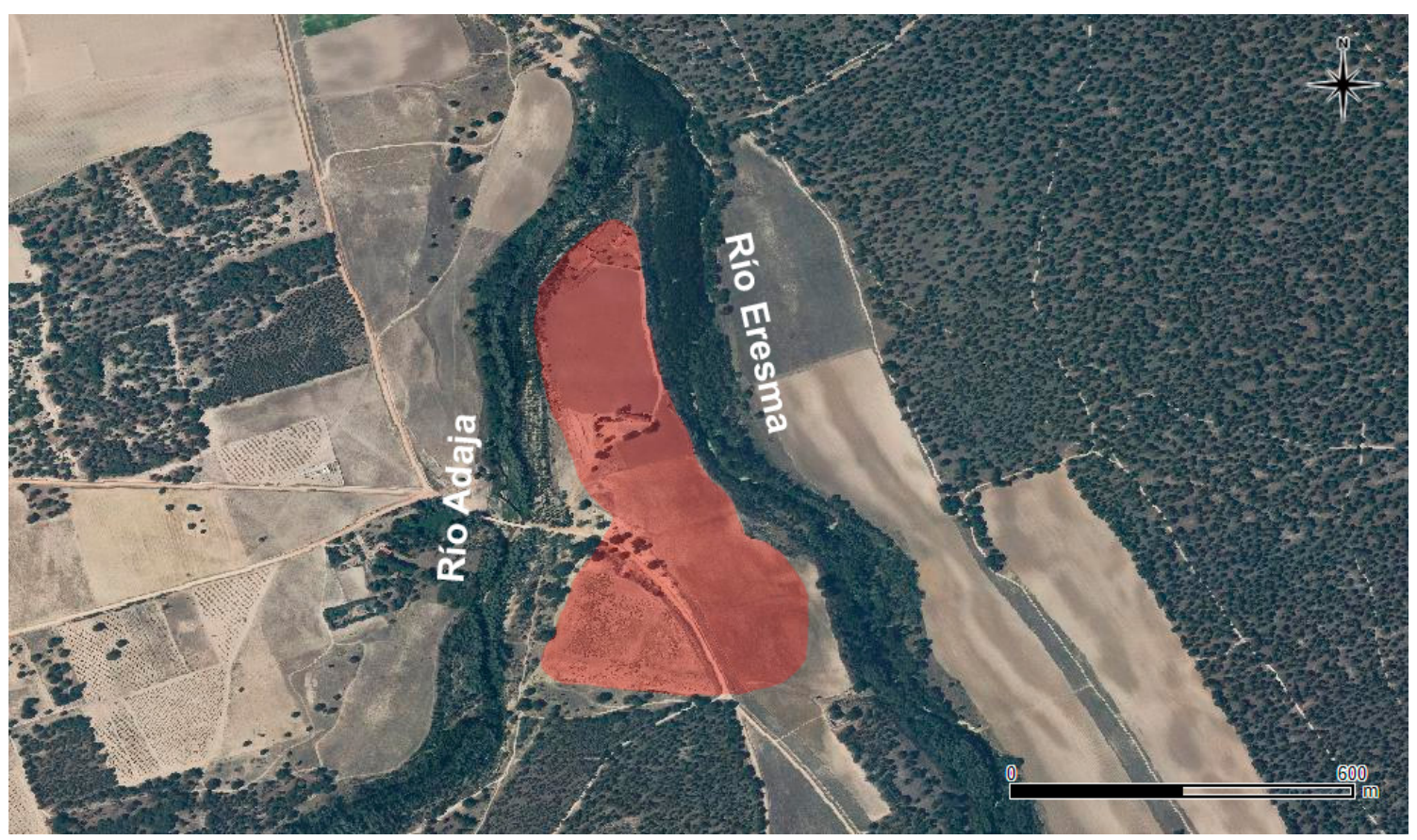

Figura 6. Fotografía aérea del yacimiento de Sieteiglesias, localizado en un espigón formado por la confluencia de los ríos Adaja y Eresma.

A lo largo del río Duero contamos con importantes núcleos como La Peña (Tordesillas, Valladolid) (Blanco González 2009a: vol. II (2): 67-70), El Viso (Madridanos, Zamora)
(Esparza 1990) en un cerro imponente que domina visualmente un amplio territorio que incluye el sitio de Los Castros/Valcuevo en Villalazán (Zamora) (Martín Valls y Delibes 
1982: 64-67), La Aldehuela (Zamora capital) en la confluencia con el río Valderaduey (Santos Villaseñor 1990), Zamora en el abrupto espigón que controla un importante vado y sobre el que se levantaría la ciudad medieval (Larrén 1999), El Castillo (Fariza, Zamora) (Ramos Fraile 2005) y el yacimiento localizado en Pereña de la Ribera (Salamanca) (López Jiménez 2003: 218-222). Estos últimos formarían parte de una de las "áreas de colonización" del Hierro I definidas por Blanco González (2010a: fig. 6), situada en la comarca de Los Arribes del Duero. En el tramo alto del río Tormes destaca la conocida estación de Las Paredejas (Medinilla, Ávila) en la ladera del Cerro del Berrueco, que constituye una atalaya privilegiada sobre el entorno y un elemento visible desde lejos (Fabián 2005). Aguas abajo se encuentra el Cerro de San Pelayo que, tras un aparente periodo de abandono, vuelve a ser ocupado hacia el s. V a.C. (López Jiménez y Benet 2004: 169-170). A continuación, sobresalen las aldeas del Cerro de San Vicente (Salamanca capital) y Ledesma (Salamanca) en sendos cerros elevados sobre el río, distantes entre sí unos $35 \mathrm{~km}$ (Macarro y Alario 2012; Benet et al. 1991). Por último, los valles de los ríos Huebra y Águeda constituirían las otras dos zonas de nuestra área de estudio colonizadas durante la Primera Edad del Hierro (Blanco González y López Sáez 2013: fig. 2). El descubrimiento de unos pocos fragmentos de cerámicas soteñas en los asentamientos salmantinos del Picón de la Mora (Encinasola de los Comendadores), Las Merchanas (Lumbrales) y El Castillo (Herguijuela de Ciudad Rodrigo) permite plantear la vinculación de estas zonas al mundo del Soto durante esta etapa de plenitud (Martín Valls 1998: 141-142; Esparza y Blanco González 2008: 89).

Sin duda los patrones de poblamiento del Soto Inicial y Pleno esbozados aquí sufrirían modificaciones sustanciales si fuéramos capaces de adscribir temporalmente los 50 enclaves clasificados de manera genérica como pertenecientes al grupo Soto. A partir de la mayor similitud que presentan dichos núcleos y los sitios del periodo inicial del Soto (Tabla 1) podríamos pensar que el grueso de los yacimientos sin una cronología concreta perteneciera al Soto Inicial, aunque es obvio que los indicios son insuficientes. De hecho, de admitir la existencia de una auténtica colonización de Los Arribes del Duero y los valles del Huebra y el Águeda, tendríamos que incluir las estaciones indefinidas temporalmente de estas áreas en la etapa de plenitud del mundo del Soto. Lamentablemente, el elevado grado de imprecisión aún existente impide confirmar la jerarquización del poblamiento que parece intuirse, al menos, en las zonas más densamente pobladas del área de estudio durante la fase soteña más reciente (Blanco García 2006b: 492).

Tabla 1. Tabla sintética de las características básicas del poblamiento de la Edad del Hierro en el suroeste de la cuenca del Duero.

\begin{tabular}{|c|c|c|c|c|}
\cline { 2 - 5 } \multicolumn{1}{c|}{} & Grupo Soto & Soto Inicial & Soto Pleno & Hierro II \\
\hline Altitud media (m s.n.m.) & 853 & 844 & 804 & 820 \\
\hline Superficie media (ha) & 2,16 & 5,45 & 6,55 & 11,24 \\
\hline Emplazamiento preferente & Loma & Loma & Espigón & Cerro río \\
\hline Cauce fluvial & Secundario & Secundario & Principal & Principal \\
\hline
\end{tabular}

\section{La transición Hierro I-Hierro II}

En nuestra área de estudio la gran mayoría de los autores aceptan una cierta continuidad entre la Primera y la Segunda Edad del Hierro (p. ej. Fernández-Posse 1998: 155; ÁlvarezSanchís 2003: 101 y 332; Romero et al. 2008: 678). A pesar de ello, los profundos cambios que se observan en el registro arqueológico alrededor del 400 cal AC justifican la distinción de una nueva fase. En lo que respecta al poblamiento, en este momento se produce el abandono de sitios emblemáticos del Hierro Antiguo como La Mota (Delibes et al. 1995: 83) o Los Castillejos de Sanchorreja (González-Tablas y Domínguez Calvo 2002: 240); y, en el caso de la capital salmantina, se materializa el traslado de la población desde el Cerro de San Vicente al colindante Teso de las Catedrales (Macarro y Alario 2012: 90). Así, de 43 yacimientos de la Segunda Edad del Hierro ( $c a .400-50$ cal AC) en el suroeste de la 
cuenca del Duero, 20 son establecimientos de nueva planta, es decir, el 47\%. Además, a partir de esa fecha se produce una aceleración en el proceso de concentración de la población en núcleos más grandes (Fernández-Posse
1998: 161; Romero et al. 2008: 682), lo que provocará que durante el Hierro II aumente ostensiblemente la superficie de una parte de los enclaves ocupados desde la fase anterior (Fig. 7).

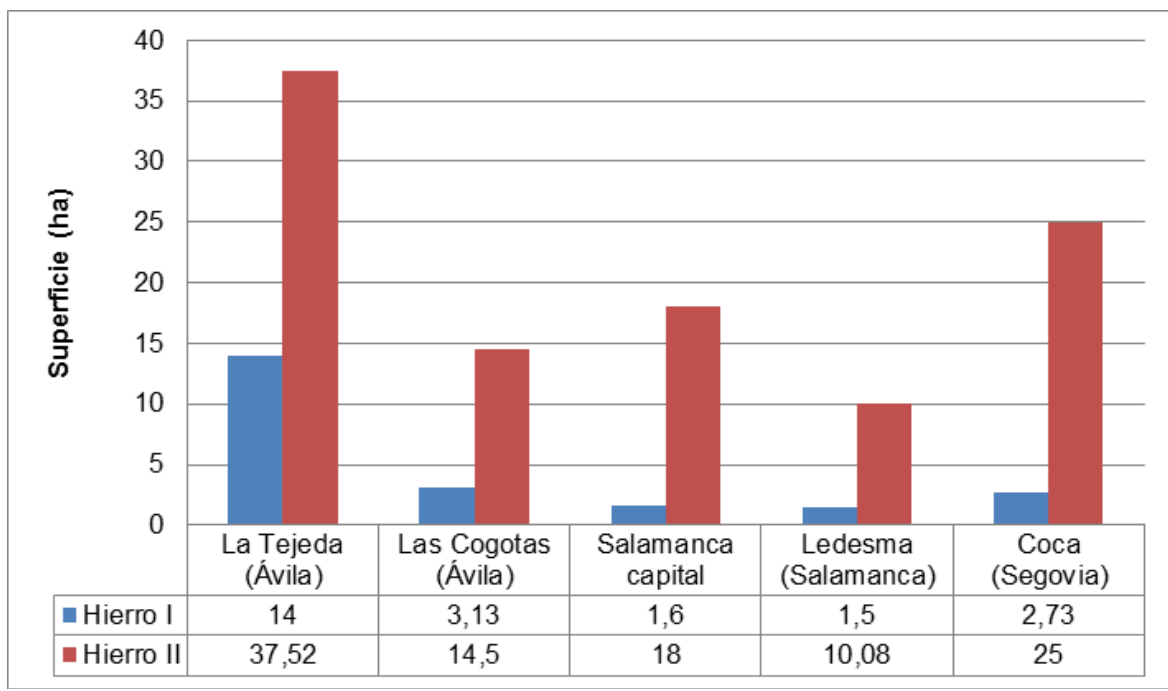

Figura 7. Variación en la superficie de algunos poblados del suroeste de la Meseta Norte ocupados durante las dos fases de la Edad del Hierro.

Uno de los factores clave a tener en cuenta a la hora de explicar el proceso de cambio detectado en la Meseta hacia el $400 \mathrm{cal} \mathrm{AC}$ es el visible crecimiento demográfico experimentado por las comunidades del Hierro Inicial (Esparza 1995: 140; Fernández-Posse 1998: 154; Blanco González 2010a; c; 2018: 309-310). Este auge poblacional podría haber provocado, al final del periodo, una creciente necesidad de acceso a recursos básicos para asegurar el sostenimiento de grupos cada vez más numerosos. Ante esta situación las comunidades de finales del Hierro I parecen haber puesto en marcha dos tipos de estrategias distintas: 1) en las zonas más densamente pobladas de la cuenca del Duero se produjo una concentración de la población en unos pocos núcleos, bastante distanciados entre sí (Sacristán 1989; 2011; Sacristán et al. 1995), en un proceso de sinecismo voluntario o forzado que cristalizó en las primeras ciudades u oppida; 2) en las áreas menos pobladas se habría llevado a cabo una colonización de nuevos terrenos, a través de movimientos migratorios de corto alcance a lo largo de los principales ríos, como los descritos para la Primera Edad del Hierro, fundándose de esta manera una serie de nuevas estaciones a partir del excedente demográfico de las aldeas preexistentes. Esta "colonización pionera encadenada" (Blanco González 2010c: 173) habría afectado fundamentalmente a los valles de los ríos Huebra, Águeda, Alagón, Jerte y Almonte, estos tres últimos fuera del ámbito de análisis de este trabajo. No obstante, en algunas de estas áreas de colonización surgirán también una serie de oppida en un momento tardío del Hierro II (ss. II-I a.C.).

\section{La Segunda Edad del Hierro y la aparición de las primeras ciudades}

A lo largo del Hierro II aparecieron en la mayor parte del área de estudio un conjunto de núcleos de gran tamaño u oppida, que albergarían en algunos casos miles de habitantes y pueden considerarse las primeras ciudades de la Meseta (Álvarez-Sanchís 2011). En este trabajo se ha denominado como oppidum todo aquel yacimiento con un tamaño mínimo de 10 ha, debido a que se ha constatado la existencia de una ruptura con respecto al resto de poblados, que no superan en ningún caso las 6 ha. Estos núcleos urbanos, al igual que sucede en la Europa Templada (Fichtl 2005: 107 y ss.), constituyen importantes centros económicos, político-religiosos y defensivos que controlan un territorio amplio. 


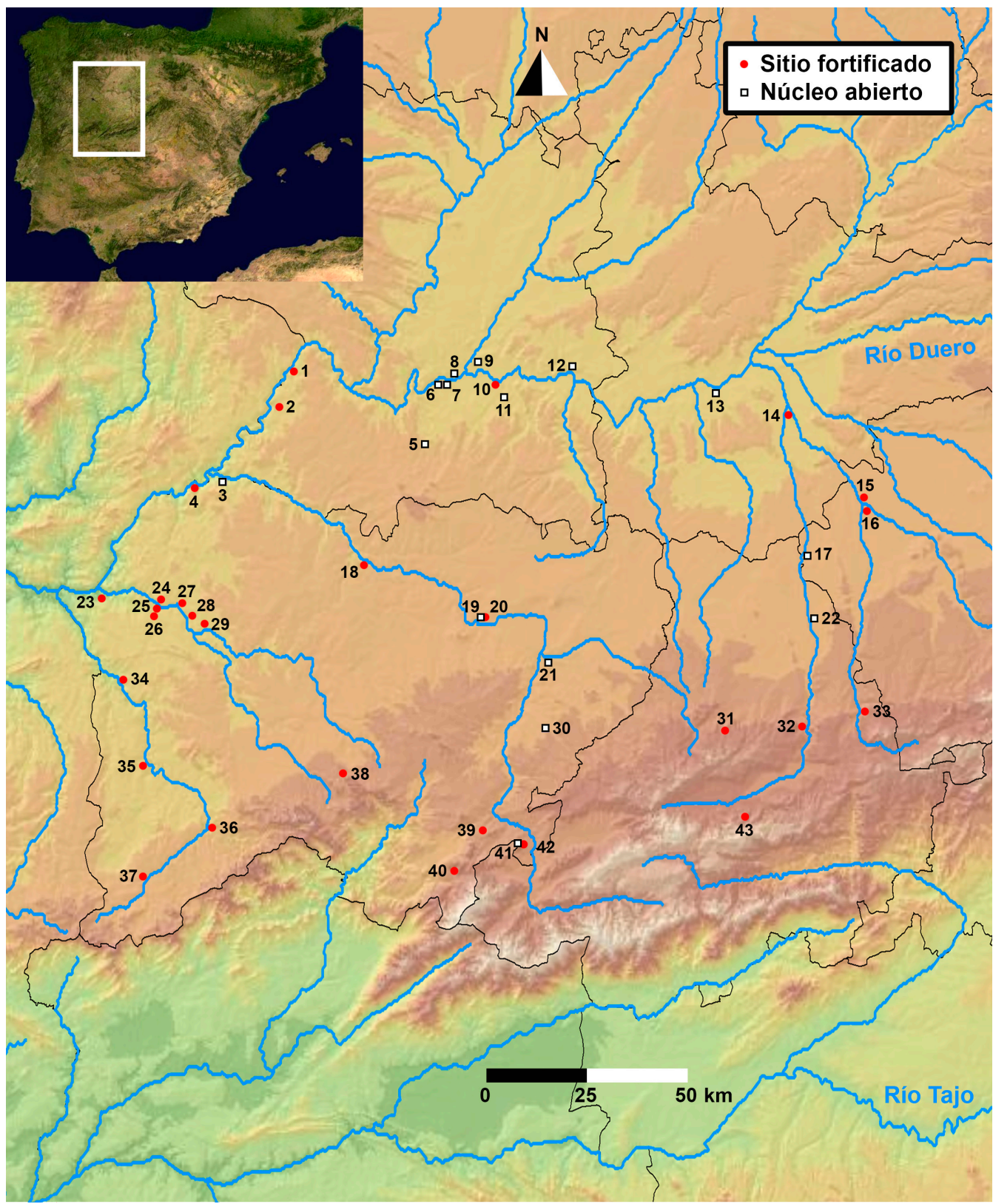

Figura 8. Poblamiento del Hierro II en el suroeste de la cuenca del Duero: 1. San Mamede/Peña Redonda (Villardiegua de la Ribera); 2. El Castillo (Fariza); 3. Teso de San Cristóbal (Villarino de los Aires); 4. Virgen del Castillo (Pereña de la Ribera); 5. Los Castillos (La Tuda, Pereruela); 6. El Castro (Zamora); 7. Teso del Castro (Zamora); 8. Zamora; 9. Valdegallinas II (Zamora); 10. Los Castros/ Valcuevo (Villalazán); 11. El Viso (Madridanos); 12. Toro; 13. La Peña (Tordesillas); 14. Sieteiglesias (Matapozuelos); 15. Cuesta del Mercado (Coca); 16. Coca; 17. La Puente (Donhierro); 18. Ledesma; 19. Cerro de San Vicente (Salamanca); 20. Teso de las Catedrales (Salamanca); 21. Cuesta de Santa Ana (Garcihernández); 22. La Tejeda (Orbita); 23. Cabeza de Moncalvo (Hinojosa de Duero); 24. El Castillo

(Saldeana); 25. Castillo de Saldañuela (Bermellar); 26. Las Merchanas (Lumbrales); 27. Picón de la Mora (Encinasola de los Comendadores); 28. Los Castillos (Yecla de Yeltes); 29. Yecla la Vieja (Yecla de Yeltes); 30. Los Ocuestos (Alaraz); 31. La Mesa de Miranda (Chamartín); 32. Las Cogotas (Cardeñosa);

33. San Juan (Ojos-Albos); 34. Castelmao (San Felices de los Gallegos); 35. La Plaza (Gallegos de Argañán); 36. Lerilla (Zamarra); 37. Irueña (Fuenteguinaldo); 38. La Corona (Rinconada de la Sierra); 39. El Castillo (Cabeza de Béjar); 40. La Corvera (Navalmoral de Béjar); 41. Las Paredejas (Medinilla); 42. 
En esta fase existen también dentro de nuestra zona de estudio notables diferencias territoriales en el volumen de información disponible sobre la ocupación del territorio. Para el Hierro II contamos con 23 yacimientos excavados $(53 \%$ del total de sitios conocidos), distribuidos de forma equilibrada por el suroeste de la cuenca del Duero. Sin embargo, carecemos de información sobre el poblamiento de esta etapa en los valles de los ríos Zapardiel, Trabancos y Guareña (comarcas de la Tierra de Medina y La Guareña). A continuación, analizaremos las características básicas del poblamiento de la Segunda Edad del Hierro en el suroeste de la Meseta Norte. Para ello, vamos a organizar nuestra exposición a partir de los ríos más importantes de esta zona, debido a que la mayor parte de los asentamientos de este momento se ubican junto a la red fluvial principal (Fig. 8).

\section{a) Ríos Voltoya-Eresma:}

En el valle del río Eresma se ha planteado la existencia de un modelo de poblamiento configurado por una serie de poblados ubicados junto a su cauce, en lugares estratégicos bien defendidos y próximos a las mejores tierras de cultivo. A partir de las considerables dimensiones que debieron alcanzar Segovia, Coca y Simancas (en la orilla derecha del Duero) en estos momentos, se ha defendido una jerarquización lineal del poblamiento, según la cual en un punto intermedio entre estas grandes poblaciones habría otras de segundo orden (Cerro de la Virgen de Tormejón en Armuña -Segovia-y Sieteiglesias) (Blanco García 2006a: 42-58). El problema es que, en el caso de Sieteiglesias, parece difícil considerarlo un sitio secundario, cuando tiene una extensión similar (Sacristán et al. 1995: tabla 2) o incluso superior a la de Simancas (Blanco González 2009a: vol. II (2): 316). Quizá relacionado de alguna manera con este corredor del Eresma estaría el pequeño castro abulense de San Juan (Ojos-Albos), localizado junto al río Voltoya (principal afluente del Eresma) y con una posible ocupación prerromana (Blanco González 2009b: 161). De este modo, el poblamiento en estos valles fluviales se caracteriza por su situación en espigones sobre los cauces principales (Fig. 9), con un fácil acceso a fértiles terrenos de cultivo y a pastizales y recursos forestales en el caso de San Juan. Excluyendo el yacimiento abulense, el resto de enclaves se encuentran ubicados a una altitud muy similar (entre los 712 y los 785 m s.n.m.). Más diferencias hay en cuanto a su tamaño, puesto que Coca más su anejo de la Cuesta del Mercado prácticamente duplican la superficie de Sieteiglesias (Fig. 10), aunque la considerable distancia que los separa (30 $\mathrm{km})$ parece asegurar la independencia y autonomía de la estación vallisoletana.

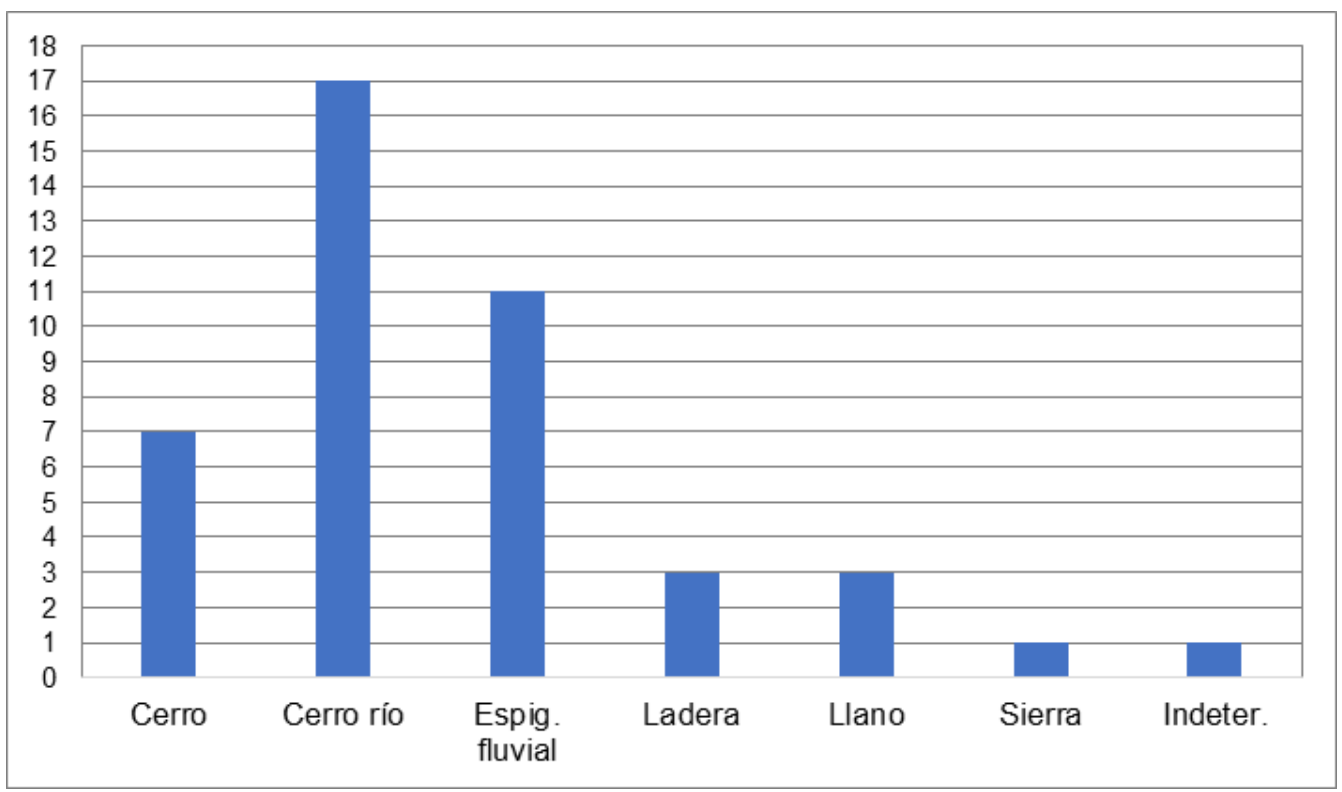

Figura 9. Tipos de emplazamiento de los enclaves del Hierro II en el suroeste de la Meseta Norte. 

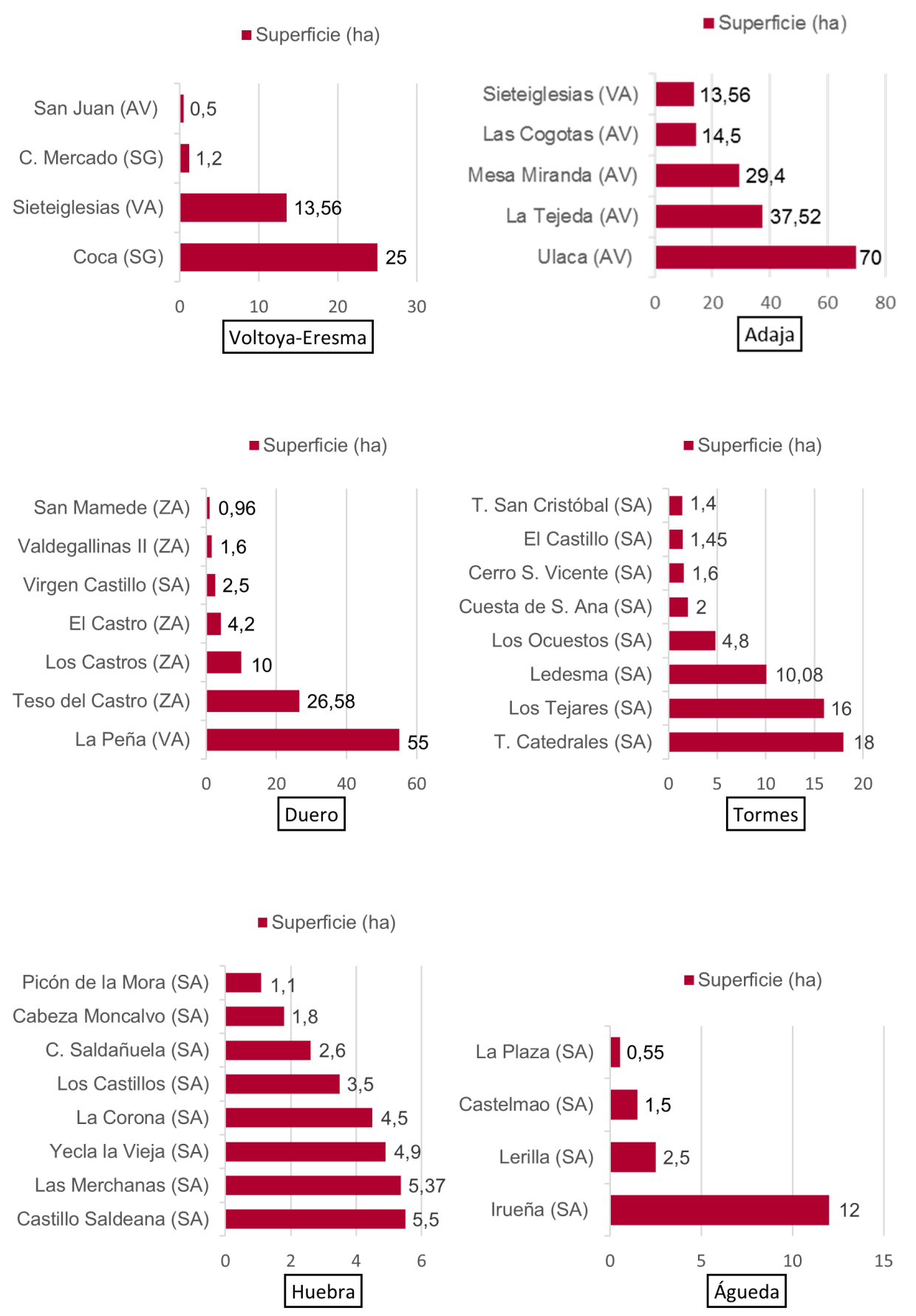

Figura 10. Tamaño de los asentamientos del Hierro II localizados en torno a los principales cauces fluviales del suroeste de la cuenca del Duero.

b) Río Adaja:

Para la cabecera del río Adaja o Valle Amblés se ha propuesto un patrón de poblamiento jerarquizado, formado por asentamientos fortificados de grandes dimensiones, localizados en las estribaciones de las sierras que circundan el valle, y núcleos menores situados en las zonas llanas próximas al cauce del río (Álvarez-Sanchís 2003: 115-120; Ruiz Zapatero y Álvarez-Sanchís 1995: 226-230). Sin embargo, dicho modelo está basado en los datos proporcionados por la Carta Arqueológica provincial de Ávila que responde "más a una recopilación de noticias orales y escritas 
(muy parcas y antiguas) que a una labor de campo sistemática y concienzuda" (Hernando Sobrino 1994: 24). Así, los establecimientos del fondo del valle sólo se conocen a partir de hallazgos escasos (fundamentalmente cerámicos), cuyo lugar exacto de procedencia se sabe a veces con muchas dudas, lo que impide confirmar que se trate de verdaderos poblados y asignarles una cronología firme. Por ello, mientras Álvarez-Sanchís (2003: 130) los sitúa en un momento avanzado de la Segunda Edad del Hierro, reservando para ellos una posición subordinada a la de los oppida serranos, Hernando Sobrino (1994: 350) los vincula al período que va entre mediados del s. I a.C. y el s. II d.C., poniéndolos en relación con la capital abulense y la reorientación romana de la economía hacia la explotación de los recursos agrícolas. Sin embargo, los diferentes trabajos de prospección llevados a cabo en los últimos años al sur del Duero, incluyendo aquellos realizados en los municipios del Valle Amblés con supuestos materiales del Hierro II, no han conseguido identificar restos pertenecientes a estos sitios menores ubicados en el llano ( $\mathrm{Fa}-$ bián 2012: 223). De igual modo, en las prospecciones de muestreo sistemático y regular del área occidental del Valle Amblés (entre los oppida abulenses de Ulaca-Solosancho-y La Mesa de Miranda -Chamartín-) (Ruiz Zapatero y Álvarez-Sanchís 1999: 46-47), realizadas entre 1997 y 2003, no se han encontrado vestigios de asentamientos menores adscribibles al Hierro Pleno (Collis 2008: 73), como hemos podido constatar en nuestra revisión preliminar de los materiales procedentes de dichas prospecciones.

En el curso medio-bajo del río Adaja contamos con el extenso yacimiento abierto de $\mathrm{La}$ Tejeda (Blanco González 2009a: vol. II (2): 81-86), con el dudoso núcleo de La Puente (Donhierro, Segovia) (Blanco García 2006b: 457-458) y con la ya mencionada estación de Sieteiglesias (Bellido y Cruz 1993). Así, el poblamiento situado a lo largo del cauce del Adaja se caracteriza por su emplazamiento tanto en zonas serranas como de ribera, en relación directa con uno o varios cursos fluviales, y con una variedad de recursos agropecuarios en su entorno inmediato, como se puede comprobar en el análisis del territorio de explotación de Ulaca: un $60 \%$ del mismo estaría formado por pastizales, los suelos cultivables constituirían aproximadamente el $32 \%$, el bosque alrededor de un 3\% y los suelos improductivos un 5\%
(Ruiz Zapatero 2005: 31-32). Los oppida serranos se encuentran localizados a una altitud que oscila entre los 1508 y los 1122 m s.n.m., mientras que los poblados ubicados en la campiña se sitúan entre los 854 y los 712 m s.n.m. Uno de los rasgos más destacados de los yacimientos localizados en torno al río Adaja es su gran tamaño (exceptuando el sitio abierto de La Puente), ya que Ulaca con sus 70 ha es el enclave de mayores dimensiones de todo el área de estudio y el resto de núcleos superan las 10 ha. No obstante, la distancia existente entre ellos, superior a los $20 \mathrm{~km}$, posibilitó el control por parte de sus crecientes poblaciones de un territorio amplio, con recursos suficientes para asegurar el sostenimiento del grupo.

\section{c) Río Duero:}

En torno al río Duero se ha sugerido la existencia de un modelo de poblamiento escasamente jerarquizado, adaptado a los principales corredores fluviales y compuesto casi exclusivamente por asentamientos de grandes dimensiones, bastante distanciados entre sí (Sacristán 1989; 2011; Sacristán et al. 1995). Este patrón, planteado inicialmente para la cuenca media del Duero, se ha extendido hasta Salamanca capital y el Sayago (Sacristán 2011: fig. 1). Sin embargo, mientras lo primero parece razonable, lo segundo entra en contradicción con las características del modelo, ya que los poblados identificados hasta el momento en la comarca de Sayago tienen una superficie más reducida (Ramos Fraile 2005). Por ello, el límite occidental de dicho patrón de poblamiento habría que situarlo aproximadamente a la altura de Zamora capital. De este modo, los yacimientos ubicados a lo largo del río Duero se distinguen, entre otros aspectos, por sus diferentes tamaños. Su emplazamiento preferente son los cerros cercanos o inmediatos al cauce de dicho río, localizados a una altitud que oscila entre $\operatorname{los} 782$ y los 652 m s.n.m. Las distancias entre vecinos más próximos, calculadas por Sacristán (2011: 187) a lo largo del Duero, serían: La Peña-Toro, 36 km; Toro-Los Castros de Villalazán, 18 km y Los Castros de Villalazán-Zamora, $12 \mathrm{~km}$. En cuanto a la explotación agrícola y ganadera del territorio, ante la ausencia de alquerías subordinadas, sería realizada directamente desde los grandes sitios conocidos.

d) Río Tormes:

Según Martín Valls (1998: 167-169) y López Jiménez (2003: 269 y ss.), los enclaves de 
la Segunda Edad del Hierro de la provincia de Salamanca se pueden agrupar en tres conjuntos diferentes a partir de su distribución geográfica y sus rasgos distintivos: 1) las estaciones del curso Alto del Tormes y de las zonas serranas del sureste de la provincia; 2) los núcleos del curso medio del Tormes; 3) los asentamientos de la zona occidental, situados en el Bajo Tormes, Yeltes-Huebra y Águeda. Centrándonos en los poblados ubicados en el valle del río Tormes, sus diferentes emplazamientos y tamaños parecen corroborar la clasificación propuesta por estos autores. Así, los yacimientos del Alto Tormes se caracterizan por su localización en cerros elevados (entre los 1103 y los 943 m s.n.m.), alejados del cauce del río. Por su parte, los sitios del curso medio del Tormes ocupan cerros inmediatos a este río o al río Almar (su principal afluente), situados a una altitud que oscila entre los 848 y los 775 m s.n.m. La principal diferencia de estos últimos con respecto al Teso de San Cristóbal (Villarino de los Aires, Salamanca), ubicado también en un cerro muy cerca de la desembocadura del Tormes, es su mayor tamaño -especialmente en el caso del Teso de las Catedrales y Ledesma-. El grupo de estaciones del Alto Tormes ha sido puesto en relación con el control de la Cañada de Béjar y los pasos entre la Alta Extremadura y Salamanca, mientras que los enclaves del curso medio del río Tormes se dedicarían a la explotación agropecuaria de sus amplios territorios (López Jiménez 2003: 269 y ss.; Benet y López Jiménez 2008: 168-170). En este último ámbito, las distancias entre vecinos más próximos serían: Cuesta de Santa Ana-Teso de las Catedrales, 19 km; Teso de las Catedrales-Ledesma, $35 \mathrm{~km}$ y LedesmaTeso de San Cristóbal, 42 km.

\section{e) Río Huebra:}

En torno al río Huebra se ha propuesto un patrón de poblamiento configurado por pequeños núcleos, fuertemente fortificados, localizados junto a su cauce (Martín Valls 1998: 167-169; Álvarez-Sanchís 2003: 120; López Jiménez 2003: 300 y ss.; Benet y López Jiménez 2008: 170; Hernández Sánchez 2011: 144-145). Destaca especialmente la concentración de los mismos, ya que en un radio de $10 \mathrm{~km}$ en torno al Picón de la Mora se encuentran los castros de Yecla la Vieja y Los Castillos en Yecla de Yeltes, El Castillo de Saldeana, Castillo de Saldañue- la (Bermellar) y Las Merchanas. Esta gran concentración de asentamientos fortificados en el noroeste de Salamanca ha sido explicada habitualmente a partir de la explotación de los recursos mineros de la zona (Salinas 1992-93: 179-180; Martín Valls 1998: 166; Álvarez-Sanchís 2003: 122), aunque no hay evidencias arqueológicas que corroboren esta actividad en época prerromana (López Jiménez 2003: 72 y ss.; Hernández Sánchez 2011: 145). Recientemente, González-Tablas (2008) ha planteado que dicha concentración de castros fuera el resultado de una política romana de reubicación de los habitantes de los poblados abulenses y del oriente salmantino en esta zona occidental, llevada a cabo en los momentos finales de la República y los inicios del Imperio. El problema es que esta propuesta se basa, entre otras cosas, en considerar a la mayor parte de los castros del Huebra como fundaciones realizadas durante el proceso de conquista o incluso en momentos posteriores, algo que a día de hoy es difícil de dilucidar debido a nuestro escaso conocimiento de su secuencia temporal (Martín Valls 1998: 166). Así pues, si mantenemos el carácter prerromano de los mismos, el poblamiento en la región occidental de Salamanca, atravesada por los ríos Huebra, Yeltes y Camaces, se caracterizaría por la presencia de un buen número de castros situados en cerros y espigones sobre el cauce de dichos ríos, en un paisaje dominado por pastizales y encinares, que estaría mostrando su vocación eminentemente ganadera (Martín Valls 1998: 166). Excluyendo el sitio serrano de La Corona (Rinconada de la Sierra), la altitud a la que se encuentran estos yacimientos oscila entre los 721 y los 534 m s.n.m. Se trata en todos los casos de estaciones de pequeño y mediano tamaño, por lo que resulta difícil hablar de jerarquización (Benet y López Jiménez 2008: 170). Presentan distancias medias con el vecino más próximo inferiores a los $5 \mathrm{~km}$ (Álvarez-Sanchís 2003: 122), aunque la orografía accidentada del terreno reduce considerablemente el dominio visual de los diferentes enclaves (Mateos Leal 2016: 127-133) y complica mucho las comunicaciones. En este sentido, se pueden mencionar los castros de Saldeana y Saldañuela, ubicados uno frente al otro, a $1 \mathrm{~km}$ de distancia, visibles entre sí, pero con el cañón del Huebra entre ellos (Fig. 11) (Benet y López Jiménez 2008: 171). 


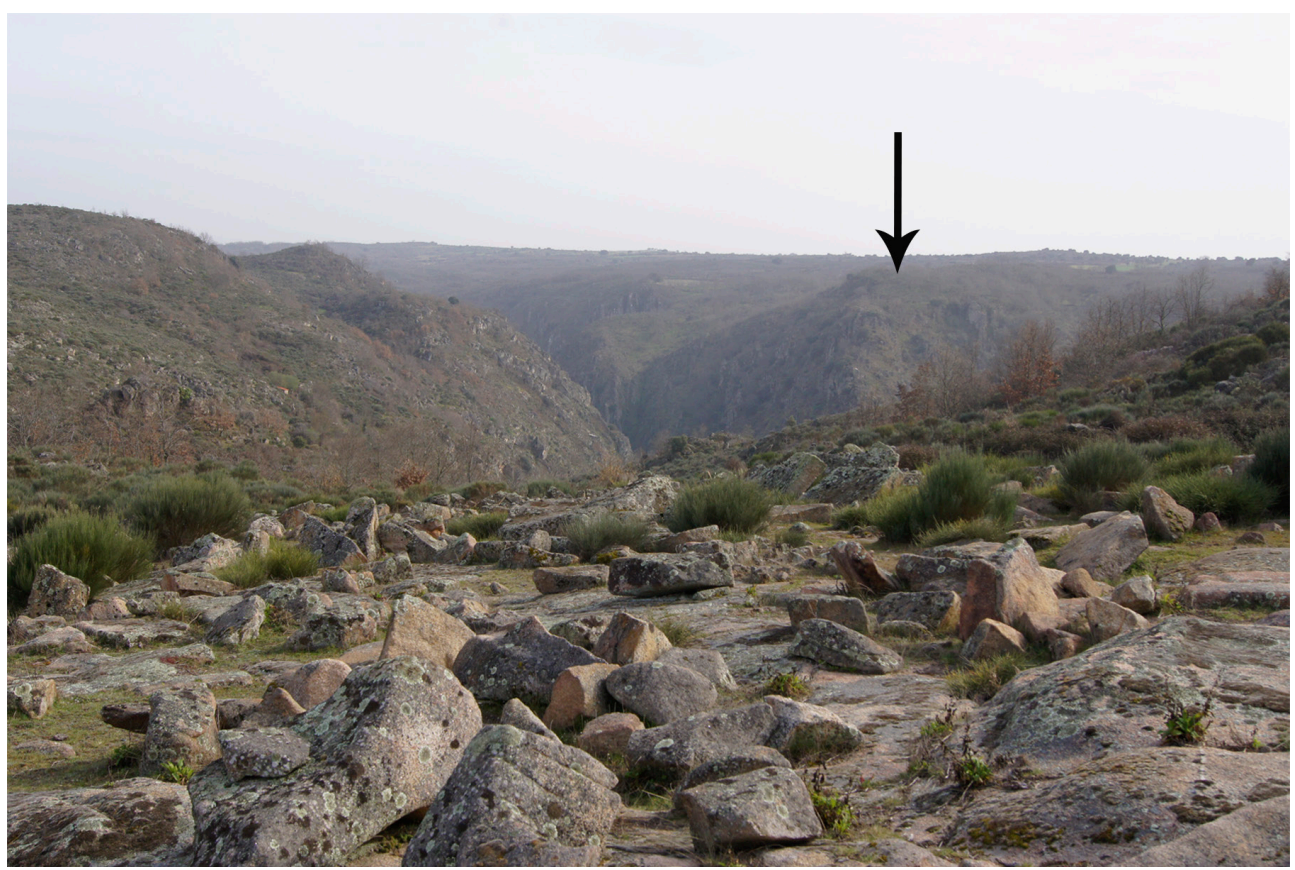

Figura 11. Vista del cerro donde se asienta el Castillo de Saldañuela, con el campo de piedras hincadas de El Castillo de Saldeana en primer término.

\section{f) Río Águeda:}

A lo largo del río Águeda también se ha planteado un modelo de poblamiento protagonizado por núcleos fortificados de pequeño tamaño, situados al lado de su cauce, aunque más distanciados que los del Huebra (Martín Valls 1998: 167-169; Álvarez-Sanchís 2003: 120; López Jiménez 2003: 316 y ss.; Benet y López Jiménez 2008: 170; Hernández Sánchez 2011: 143-144). Así, estos castros ocupan cerros y espigones sobre el Águeda, a una altitud que oscila entre los 830 y los 614 m s.n.m., en entornos con buenas posibilidades económicas y con un control casi directo de los pasos del río (Benet y López Jiménez 2008: 170). Sobresale por su tamaño el poblado de Irueña (Fuenteguinaldo, Salamanca) (Berrocal-Rangel et al. 2017), aunque su posterior ocupación en época romana podría haber distorsionado su aspecto. Uno de los rasgos más destacados de los asentamientos del Ågueda es su distribución regular a lo largo de su cauce, aproximadamente cada $20 \mathrm{~km}$, lo que posibilita que cada poblado controle un territorio amplio.

En definitiva, los patrones que acabamos de comentar permiten esbozar las características fundamentales del poblamiento del Hierro II en el suroeste de la cuenca del Duero: 1) entre los ríos Tormes y Voltoya-Eresma la población se concentraría en esta fase en una serie de grandes núcleos, bastante distanciados entre sí, que serían el resultado de los procesos de sinecismo llevados a cabo en esta zona durante la transición entre la Primera y la Segunda Edad del Hierro. 2) Estos asentamientos de grandes dimensiones $(\geq 10 \mathrm{ha}) \mathrm{u}$ oppida, carecen casi por completo de alquerías o estaciones subordinadas, al contrario de lo que sucede, por ejemplo, en el valle medio del Ebro (Burillo 2007) o en la zona mediterránea peninsular (Ruiz y Molinos 1993). 3) En el resto del área de estudio predominan los poblados fortificados de menor tamaño $(<6$ ha) o castros, muchos de los cuales son fundaciones ex novo realizadas a lo largo del cauce de los ríos Huebra y Águeda, en un proceso de colonización de nuevos espacios similar al descrito para el Hierro I. 4) En la zona colonizada del valle del Águeda aparecerá también, en un momento tardío de la Segunda Edad del Hierro (ss. II-I a.C.), un oppidum (Irueña). 5) El mayor tamaño (y población) de los sitios del Hierro II en el área de estudio, se refleja en un aumento de aproximadamente un $72 \%$ en la superficie media de los enclaves de este periodo con respecto a los de la Primera Edad del Hierro (Tabla 1).

Estos patrones de poblamiento se verán truncados por la conquista y el posterior control efectivo del suroeste de la Meseta Norte 
por parte de Roma, que a partir de la segunda mitad del siglo I a.C. impuso cambios profundos en los modelos de ocupación de este territorio. En este momento se fundaron una serie de núcleos urbanos de nueva planta como Ávila (¿Obila?) (Fabián 2007: 98) o Ciudad Rodrigo (¿Mirobriga?) (Martín Valls 1976: 384), que albergarían a las gentes provenientes de los antiguos asentamientos indígenas localizados en sus cercanías. Desde estos enclaves urbanos ex novo y otros preexistentes que continuarían habitados, como Coca (Cauca), Salamanca (Salmantica) o Ledesma (¿Bletisama?), Roma impulsará la ocupación efectiva y la explotación de zonas de alto valor agrario a través del establecimiento de una serie de villas (villae) y de otros núcleos rurales dispersos (p. ej. Ariño 2006; Blanco González et al. 2009: 279).

\section{Síntesis de un proceso}

En este apartado final vamos a condensar la lectura histórica de las grandes transformaciones y continuidades observadas en el poblamiento de los grupos protohistóricos del suroeste de la Meseta Norte a lo largo de la Edad del Hierro:

La transición Bronce Final-Hierro I ( $c a$. 1150/1100-950 cal AC) supondrá en la zona un momento de grandes cambios debido, entre otros factores, a las condiciones de aridez características de la fase final del periodo Subboreal. Ante estas condiciones ambientales adversas las comunidades del suroeste de la cuenca del Duero optaron por dos tipos de estrategias distintas: la primera de ellas, basada en la tradición, supuso la continuidad del modelo de poblamiento semipermanente típico de los grupos cogoteños, mientras que la segunda conllevó el asentamiento definitivo de las familias en localizaciones especialmente privilegiadas desde el punto de vista hídrico. Esta divergencia en el comportamiento se debería, probablemente, al diferente tamaño de los grupos humanos, siendo los menos numerosos los que adoptarían la primera estrategia, debido a su mayor facilidad para moverse por el paisaje.

De este modo, comenzaría el asentamiento definitivo de los distintos grupos en poblados permanentes y, con ello, daría comienzo la Primera Edad del Hierro (ca. 950-400 cal AC). En un primer momento, durante el Soto Inicial (ca. 950-800 cal AC), la mayor parte de los enclaves arqueológicos seguirían siendo asentamientos semipermanentes de reducido tamaño y dos o tres decenas de habitantes, pero también se ha podido constatar la presencia de auténticas aldeas. Estos establecimientos aldeanos constituyen el vestigio más visible de la apropiación efectiva del paisaje por parte de estas comunidades de los inicios de la Edad del Hierro, y, por tanto, se erigen como los nuevos marcadores del proceso de territorialización del paisaje. Dichos fenómenos se consolidarán durante el Soto Pleno ( $c a$. 800400 cal AC), a partir de la generalización del modelo aldeano, que en algunos casos habría implicado la colonización de nuevos espacios. En este momento se constata una inversión de trabajo colectivo todavía mayor en la construcción de los poblados, lo que provocará una importante alteración del paisaje previo, a través de la realización de obras de fortificación (murallas, empalizadas y fosos) en alguno de ellos. En conjunto, los establecimientos aldeanos de esta etapa acogerían a unas 200-300 personas, aunque estas cifras serían posiblemente superiores en los momentos finales de la misma.

Alrededor del 400 cal AC se observan en el registro arqueológico una serie de profundos cambios que justifican la distinción de una Segunda Edad del Hierro (ca. 400-50 cal AC). Uno de estos cambios es el abandono de alguno de los sitios más emblemáticos de la fase anterior y la concentración de la población en núcleos más grandes (ocupados previamente o ex novo), lo que dará lugar en la Meseta Norte a un patrón de poblamiento protagonizado por unos pocos núcleos bastante distanciados entre sí. Este proceso de sinecismo (voluntario o forzoso) culminaría en la aparición de las primeras ciudades u oppida. Estos núcleos, capaces de albergar miles de almas, controlarían un territorio amplio para asegurar la subsistencia de sus habitantes. En las áreas menos pobladas se produciría en este momento una colonización de nuevos terrenos, a partir del excedente demográfico de las aldeas ya existentes. No obstante, en algunas de estas áreas surgirían también enclaves de grandes dimensiones u oppi$d a$ al final del periodo (ss. II-I a.C.), momento en el que se generalizaría el modelo urbano en nuestra zona de estudio, salvo en Los Arribes del Duero y el territorio regado por el río Huebra, comarcas en las que los castros continuarían siendo los protagonistas del poblamiento.

Con la conquista romana, las formas de vida que habían caracterizado a las comunidades del suroeste de la Meseta Norte a lo largo de la Edad del Hierro se irían diluyendo paulati- 
namente debido, entre otros factores, a la importante reorganización territorial impuesta por Roma a partir de la segunda mitad del siglo I a.C. Alrededor de esta fecha aparecería en esta zona un conjunto de importantes enclaves urbanos ex novo formados a partir del traslado de la población desde los viejos castros y oppida de finales de la Edad del Hierro. Estos núcleos de nuevo cuño, unidos a los asentamientos urbanos previos que continuaron funcionando como tales, organizarían la ocupación y explotación agropecuaria de sus respectivos territorios mediante el establecimiento de una serie de villae y de otros enclaves rurales dispersos.

\section{Bibliografía}

Álvarez-Sanchís, J.R. (2003): Los Vettones. $2^{\mathrm{a}}$ ed. Real Academia de la Historia, Madrid.

Álvarez-Sanchís, J.R. (2011): Ciudades vettonas. En J.R. Álvarez-Sanchís, A. Jimeno y G. Ruiz Zapatero (eds.): Aldeas y ciudades en el primer milenio a.C. La Meseta Norte y los orígenes del urbanismo. Complutum, 22(2): 147-183.

Ariño, E. (2006): Modelos de poblamiento rural en la provincia de Salamanca (España) entre la Antigüedad y la Alta Edad Media. Zephyrus, LIX: 317-337.

Bellido, A. y Cruz, P.J. (1993): Notas sobre el yacimiento protohistórico de Sieteiglesias (Matapozuelos, Valladolid). En F. Romero, C. Sanz Mínguez y Z. Escudero (eds.): Arqueología vaccea. Estudios sobre el mundo prerromano en la cuenca media del Duero. Junta de Castilla y León, Valladolid: 263-277.

Benet, N.; Jiménez, M.C. y Rodríguez, M.B. (1991): Arqueología en Ledesma, una primera aproximación: la excavación en la Plaza de San Martín. En M. Santonja (coord.): Del Paleolítico a la Historia. 2a ed. Junta de Castilla y León, Salamanca: 117-136.

Benet, N. y López Jiménez, O. (2008): Investigaciones recientes en la Edad del Hierro en Salamanca y la Beira Alta: los castros del occidente. En J.R. Álvarez-Sanchís (ed.): Arqueología Vettona. La Meseta Occidental en la Edad del Hierro. Zona Arqueológica, 12. Museo Arqueológico Regional, Alcalá de Henares: 162-181.

Berrocal-Rangel, L.; Paniego Díaz, P.; Ruano, L. y Manglano Valcárcel, G.R. (2017): Aplicaciones LiDAR a la topografía arqueológica: el castro de Irueña (Fuenteguinaldo, Salamanca). Cuadernos de Prehistoria y Arqueología de la Universidad Autónoma de Madrid, 43: 195-215.

Blanco García, J.F. (1994): El castro protohistórico de la Cuesta del Mercado (Coca, Segovia). Cuadernos de Prehistoria y Arqueología de la Universidad Autónoma de Madrid, 21: 35-80.

Blanco García, J.F. (2006a): El paisaje poblacional segoviano en época prerromana: ocupación del territorio y estrategias de urbanización. Oppidum. Cuadernos de investigación, 2: 35-84.

Blanco García, J.F. (2006b): El primer milenio a. C. en el noroeste de Segovia. Hacia la formación de Cauca (Coca). (Siglos XI-V a. C.). Ediciones de la Universidad Autónoma de Madrid, Madrid.

Blanco González, A. (2009a): El poblamiento del Bronce Final y Primer Hierro en el sector meridional de la Submeseta Norte. 2 vols. Universidad de Salamanca, Salamanca. (http://hdl.handle.net/10366/76407). (Acceso 13/11/2018).

Blanco González, A. (2009b): Tendencias del uso del suelo en el Valle Amblés (Ávila, España). De la Edad del Hierro al Medievo. Zephyrus, LXIII: 155-183.

Blanco González, A. (2010a): ‘Arqueología de la población’ entre la Edad del Bronce y el Primer Hierro (1800-400 AC): sobre procesos migratorios y colonizadores en la Submeseta Norte. En F. Burillo (ed.): Arqueología de la Población. Arqueología Espacial, 28: 361-379.

Blanco González, A. (2010b): La definición del Hierro Antiguo en el castro de Las Cogotas (Cardeñosa, Ávila). Consideraciones sobre algunos materiales del Museo Arqueológico Nacional. Complutum, 21(1): 123-143.

Blanco González, A. (2010c): ¿Nuevos hogares para los emigrantes? Casas y paisajes en el debate sobre el límite entre Cogotas I y el Primer Hierro en el valle del Duero. Zephyrus, LXVI: 155-179.

Blanco González, A. (2018): De cabañas a casas. Estrategias sociales en la Prehistoria Final de la Meseta (1400-400 AC). En A. Rodríguez Díaz, I. Pavón Soldevila y D.M. Duque Espino (eds.): Más allá de las 
casas. Familias, linajes y comunidades en la protohistoria peninsular. Universidad de Extremadura, Cáceres: 295-326.

Blanco González, A. y López Sáez, J.A. (2013): Dynamics of pioneer colonisation in the Early Iron Age in the Duero basin (Central Iberia, Spain): integrating archaeological and palynological records. Journal of Environmental Archaeology, 18(2): 102-113.

Blanco González, A.; López Sáez, J.A. y López Merino, L. (2009): Ocupación y uso del territorio en el sector centromeridional de la cuenca del Duero entre la Antigüedad y la Alta Edad Media (siglos I-XI d.C.). Archivo Español de Arqueología, 82: 275-300.

Burillo, F. (2007): Los Celtíberos. Etnias y Estados. $2^{\mathrm{a}}$ ed. Crítica, Barcelona.

Celestino, S.; Rafel, N. y Armada, X.-L. (eds.) (2008): Contacto cultural entre el Mediterráneo y el Atlántico (siglos XII-VIII ane). La precolonización a debate. Consejo Superior de Investigaciones Científicas, Madrid.

Collis, J. (2008): The vettones in a european context. En J.R. Álvarez-Sanchís (ed.): Arqueología Vettona. La Meseta Occidental en la Edad del Hierro. Zona Arqueológica, 12. Museo Arqueológico Regional, Alcalá de Henares: 62-77.

Criado, F. (1993): Límites y posibilidades de la Arqueología del Paisaje. SPAL, 2: 9-55.

Cunliffe, B. (1999): The Ancient Celts. Penguin Books, London.

Champion, T. (2006): The image of the Celts in the 19th century. En S. Rieckhoff (dir.): Celtes et Gaulois, l'Archéologie face à l'Histoire, 1: Celtes et Gaulois dans l'histoire, l'historiographie et l'idéologie moderne. Centre archéologique européen, Glux-en-Glenne: 123-142.

Delibes, G. y Fernández Manzano, J. (2000): La trayectoria cultural de la Prehistoria Reciente (6400-2500 BP) en la Submeseta Norte española: principales hitos de un proceso. En V.O. Jorge (coord.): Actas $3 .^{\circ}$ Congresso de Arqueologia Peninsular. Pré-História Recente da Península Ibérica. Vol. 4. ADECAP, Porto: 95-122.

Delibes, G. y Romero, F. (2011): La plena colonización agraria del valle medio del Duero. En J.R. ÁlvarezSanchís, A. Jimeno y G. Ruiz Zapatero (eds.): Aldeas y ciudades en el primer milenio a.C. La Meseta Norte y los orígenes del urbanismo. Complutum, 22(2): 49-94.

Delibes, G.; Romero, F.; Sanz Mínguez, C.; Escudero, Z. y San Miguel, L.C. (1995): Panorama arqueológico de la Edad del Hierro en el Duero medio. En G. Delibes, F. Romero y A. Morales (eds.): Arqueología y medio ambiente. El primer milenio a.C. en el Duero Medio. Junta de Castilla y León, Valladolid: 49-146.

Esparza, A. (1990): La Edad del Hierro en Zamora. En Primer Congreso de Historia de Zamora. Tomo II. Prehistoria e Historia Antigua. Instituto de Estudios Zamoranos «Florián de Ocampo», Zamora: 101126.

Esparza, A. (1995): La Primera Edad del Hierro. En J.C. Alba (coord.): Historia de Zamora. Tomo I. De los orígenes al final del Medievo. Diputación de Zamora-Instituto de Estudios Zamoranos «Florián de Ocampo»-Caja España, Zamora: 101-149.

Esparza, A. (2009): El significado de los castros del noroeste zamorano. En Actas III y IV Congreso de Antropología. Instituto de Estudios Zamoranos «Florián de Ocampo», Zamora: 29-37.

Esparza, A. y Blanco González, A. (2008): El solar de Vettonia, antes de los vettones. En J.R. ÁlvarezSanchís (ed.): Arqueología Vettona. La Meseta Occidental en la Edad del Hierro. Zona Arqueológica, 12. Museo Arqueológico Regional, Alcalá de Henares: 80-93.

Fabián, J.F. (1999): La transición del Bronce Final al Hierro I en el sur de la Meseta Norte. Nuevos datos para su sistematización. Trabajos de Prehistoria, 56(2): 161-180.

Fabián, J.F. (2005): Castro de Las Paredejas. Medinilla, Ávila. Institución "Gran Duque de Alba", Ávila.

Fabián, J.F. (2007): Los orígenes de la ciudad de Ávila y la época antigua. Aportaciones de la arqueología al esclarecimiento de las cuestiones históricas previas a la etapa medieval. En Ávila en el tiempo. Homenaje al profesor Ángel Barrios. Vol. I. Institución "Gran Duque de Alba", Ávila: 83-111.

Fabián, J.F. (2012): Todos los paisajes del Valle Amblés. En Institución Gran Duque de Alba 1962-2012: 50 años de cultura abulense. Vol. I. Institución Gran Duque de Alba, Ávila: 213-229.

Fernández-Posse, M.D. (1998): La investigación protohistórica en la Meseta y Galicia. Síntesis, Madrid.

Fernández-Posse, M.D. y Sánchez-Palencia, F.J. (1998): Las comunidades campesinas en la Cultura Castreña. Trabajos de Prehistoria, 55(2): 127-150.

Fichtl, S. (2005): La ville celtique. Les oppida de 150 av. J.-C. à 15 ap. J.-C. $2^{\mathrm{a}}$ ed. Errance, Paris.

González Ruibal, A. (2006-07): Galaicos. Poder y comunidad en el Noroeste de la Península Ibérica (1200 a.C. -50 d.C.). Brigantium, 18-19. Museo Arqueolóxico e Histórico, A Coruña. 
González-Tablas, F.J. (2008): Los castros del occidente salmantino. Edad del Hierro y romanización. Zephyrus, LXII: 139-149.

González-Tablas, F.J. y Domínguez Calvo, A. (2002): Los Castillejos de Sanchorreja (Ávila): campañas de 1981, 1982 y 1985. Ediciones Universidad de Salamanca, Salamanca.

Hernández Sánchez, D. (2011): El poblamiento castreño del occidente salmantino. En J.P. López García, D. Hernández Sánchez y J. García Sánchez (eds.): Los vínculos entre el hábitat y el paisaje. Actas del I Congreso de Arqueología de Chamartín (Ávila). Ediciones de La Ergástula, Madrid: 139-148.

Hernando, A. (2002): Arqueología de la Identidad. Akal, Madrid.

Hernando Sobrino, M.R. (1994): Indigenismo y romanización del territorio abulense (s. V a. C. - s. III d. C.). Universidad Complutense de Madrid, Madrid. (http://eprints.ucm.es/2408/1/H0023201.pdf). (Acceso 25/11/2018).

Larrén, H. (1999): La evolución urbana de la ciudad de Zamora a través de los vestigios arqueológicos. En F. Valdés (coord.): La Península Ibérica y el Mediterráneo entre los siglos XI y XII -III-: el urbanismo de los estados cristianos peninsulares. Fundación Santa María la Real, Aguilar de Campoo: 91-118.

López Jiménez, O. (2003): Protohistoria del occidente de la Meseta Norte: estructura social y territorio. Tesis Doctoral inédita, Universidad Complutense de Madrid.

López Jiménez, O. y Benet, N. (2004): Nuevos resultados en la investigación sobre 'La Plaza de Toros' del Cerro de San Pelayo (Martinamor, Salamanca): un enterramiento tumular con inhumación en los inicios del primer milenio en el área occidental de la Meseta Norte. Trabajos de Prehistoria, 61(1): 157-173.

López Sáez, J.A. y Blanco González, A. (2005): La mutación Bronce Final/Primer Hierro en el suroeste de la Cuenca del Duero (provincia de Ávila): ¿cambio ecológico y social? En A. Blanco, C. Cancelo y A. Esparza (eds.): Bronce Final y Edad del Hierro en la Península Ibérica. Encuentro de Jóvenes Investigadores. Ediciones Universidad de Salamanca, Salamanca: 229-250.

López Sáez, J.A.; Blanco González, A.; López Merino, L.; Ruiz Zapata, M.B.; Dorado Valiño, M.; Pérez Díaz, S.; Valdeolmillos, A. y Burjachs, F. (2009): Landscape and climatic changes during the end of the Late Prehistory in the Amblés Valley (Ávila, central Spain), from 1200 to 400 cal BC. Quaternary International, 200: 90-101.

Macarro, C. y Alario, C. (2012): Los orígenes de Salamanca: el poblado protohistórico del Cerro de San Vicente. Centro de Estudios Salmantinos-Fundación Salamanca Ciudad de Cultura y Saberes, Salamanca.

Marín Suárez, C. (2011): De nómadas a castreños: el primer milenio antes de la era en el sector centrooccidental de la Cordillera Cantábrica. Universidad Complutense de Madrid, Madrid. (http://eprints. ucm.es/14435/1/T33309.pdf). (Acceso 24/11/2018).

Martín Valls, R. (1976): Nuevos hallazgos arqueológicos en Ciudad Rodrigo. Zephyrus, XXVI-XXVII: 373-388.

Martín Valls, R. (1998): La Edad del Hierro. En M. Salinas (coord.): Historia de Salamanca. I. Prehistoria y Edad Antigua. $2^{\mathrm{a}}$ ed. Centro de Estudios Salmantinos, Salamanca: 123-217.

Martín Valls, R. y Delibes, G. (1982): Hallazgos arqueológicos en la provincia de Zamora (IX). Boletín del Seminario de Estudios de Arte y Arqueología, XLVIII: 45-70.

Mateos Leal, C.M. (2016): El poblamiento protohistórico del occidente de La Meseta (Sistema Central y Campo Charro). Estudio de las culturas indigenas a través de su hábitat. Universidad Autónoma de Madrid, Madrid. (http://hdl.handle.net/10486/671732). (Acceso 21/11/2018).

Misiego, J.C.; Marcos Contreras, G.J.; Martín Carbajo, M.A.; Sanz García, F.J. y Villanueva Martín, L.A. (2005): Guaya (Berrocalejo de Aragona, Ávila): reconstrucción de la vida y economía de un poblado en los albores de la Edad del Hierro. En A. Blanco, C. Cancelo y A. Esparza (eds.): Bronce Final y Edad del Hierro en la Península Ibérica. Encuentro de Jóvenes Investigadores. Ediciones Universidad de Salamanca, Salamanca: 207-228.

Ortega Ortega, J.M. (1999): Al margen de la «identidad cultural»: historia social y economía de las comunidades campesinas celtíberas. En F. Burillo (coord.): IV Simposio sobre los Celtíberos. Economía. Institución «Fernando el Católico», Zaragoza: 417-452.

Parcero, C. (2000): Tres para dos. Las formas de poblamiento en la Edad del Hierro del noroeste ibérico. Trabajos de Prehistoria, 57(1): 75-95.

Parcero, C. (2002): La construcción del paisaje social en la Edad del Hierro del noroeste ibérico. Fundación Ortegalia-Instituto de Estudios Galegos Padre Sarmiento, Ortigueira. 
Portilla Casado, R. (2015): “Cuesta El Pico”, Castrillo de la Guareña (Zamora). Un asentamiento atípico de la I Edad del Hierro al sur del Duero. En O. Rodríguez Monterrubio, R. Portilla Casado, J.C. Sastre Blanco y P. Fuentes Melgar (coords.): Fortificaciones en la Edad del Hierro: control de los recursos y el territorio. Glyphos Publicaciones, Valladolid: 534-546.

Quintana, J. y Cruz, P.J. (1996): Del Bronce al Hierro en el centro de la Submeseta Norte (consideraciones desde el Inventario Arqueológico de Valladolid). Boletín del Seminario de Estudios de Arte y Arqueología, LXII: 9-78.

Ramos Fraile, P. (2005): Poblamiento de Cogotas I y de la Edad del Hierro en la comarca de Sayago (Zamora). En A. Blanco, C. Cancelo y A. Esparza (eds.): Bronce Final y Edad del Hierro en la Península Ibérica. Encuentro de Jóvenes Investigadores. Ediciones Universidad de Salamanca, Salamanca: 293-313.

Rodríguez Díaz, A. (2009): Campesinos y «señores del campo». Tierra y poder en la protohistoria extremeña. Bellaterra, Barcelona.

Rodríguez-Hernández, J. (2019): Poder y sociedad: el oeste de la Meseta en la Edad del Hierro. Institución "Gran Duque de Alba", Ávila.

Romero, F.; Sanz Mínguez, C. y Álvarez-Sanchís, J.R. (2008): El primer milenio a.C. en las tierras del interior peninsular. En F. Gracia Alonso (coord.): De Iberia a Hispania. Ariel, Barcelona: 649-731.

Rowley-Conwy, P. (2007): From Genesis to Prehistory. The archaeological Three Age System and its contested reception in Denmark, Britain, and Ireland. Oxford University Press, Oxford.

Ruiz, A. y Molinos, M. (1993): Los Iberos. Análisis arqueológico de un proceso histórico. Crítica, Barcelona.

Ruiz Zapatero, G. (2005): Castro de Ulaca. Solosancho, Ávila. Institución "Gran Duque de Alba", Ávila.

Ruiz Zapatero, G. y Álvarez-Sanchís, J.R. (1995): Las Cogotas: Oppida and the roots of urbanism in the Spanish Meseta. En B.W. Cunliffe y S.J. Keay (eds.): Social complexity and the development of towns in Iberia: from the Copper Age to the second century AD. British Academy, London: 209-235.

Ruiz Zapatero, G. y Álvarez-Sanchís, J.R. (1999): Ulaca: la "Pompeya" vettona. Revista de Arqueología, 216: 36-47.

Sacristán, J.D. (1989): Vacíos vacceos. En F. Burillo (ed.): Fronteras. Arqueología Espacial, 13: 77-88.

Sacristán, J.D. (2011): El urbanismo vacceo. En J.R. Álvarez-Sanchís, A. Jimeno y G. Ruiz Zapatero (eds.): Aldeas y ciudades en el primer milenio a.C. La Meseta Norte y los orígenes del urbanismo. Complutum, 22(2): 185-222.

Sacristán, J.D.; San Miguel, L.C.; Barrio, J. y Celis, J. (1995): El poblamiento de época celtibérica en la cuenca media del Duero. En F. Burillo (coord.): Poblamiento celtibérico. III Simposio sobre los celtíberos. Institución «Fernando el Católico», Zaragoza: 337-367.

Salinas, M. (1992-93): El poblamiento rural antiguo de la provincia de Salamanca: modelos e implicaciones históricas. En J.G. Gorges y M. Salinas (eds.): El medio rural en Lusitania romana. Formas de hábitat y ocupación del suelo. Studia Historica. Historia Antigua, X-XI: 177-188.

Santos Villaseñor, J. (1990): Un yacimiento de la Primera Edad del Hierro, con cerámicas pintadas, en La Aldehuela (Zamora). En Primer Congreso de Historia de Zamora. Tomo II. Prehistoria e Historia Antigua. Instituto de Estudios Zamoranos «Florián de Ocampo», Zamora: 225-239.

Seco, M. y Treceño, F.J. (1995): Perfil arqueológico de un poblado de la Edad del Hierro al sur del Duero: "La Mota", Medina del Campo. En G. Delibes, F. Romero y A. Morales (eds.): Arqueología y medio ambiente. El primer milenio a.C. en el Duero Medio. Junta de Castilla y León, Valladolid: 219-245.

Torres Rodríguez, J. de (2013): La tierra sin límites. Territorio, sociedad e identidades en el valle medio del Tajo (s. IX-I a.C.). Zona Arqueológica, 16. Museo Arqueológico Regional, Alcalá de Henares.

Wells, P.S. (2011): The Iron Age. En S. Milisauskas (ed.): European Prehistory. A survey. $2^{\mathrm{a}}$ ed. Springer, New York: 405-460.

Williams, M. (2003): Growing metaphors. The agricultural cycle as metaphor in the later prehistoric period of Britain and North-Western Europe. Journal of Social Archaeology, 3(2): 223-255.

\section{Notas}

1. Los datos relativos a la ubicación, tamaño y cronología de todos los sitios considerados en este estudio pueden consultarse en el anexo I de Rodríguez-Hernández 2019. 